\title{
Calibration of a convective parameterization scheme in the WRF model and its impact on the simulation of East Asian summer monsoon precipitation
}

\author{
Ben Yang $\cdot$ Yaocun Zhang $\cdot$ Yun Qian • \\ Anning Huang • Huiping Yan
}

Received: 6 November 2013/Accepted: 10 March 2014/Published online: 26 March 2014

(c) The Author(s) 2014. This article is published with open access at Springerlink.com

\begin{abstract}
Reasonably modeling the magnitude, southnorth gradient and seasonal propagation of precipitation associated with the East Asian summer monsoon (EASM) is a challenging task in the climate community. In this study we calibrate five key parameters in the Kain-Fritsch convection scheme in the WRF model using an efficient importance-sampling algorithm to improve the EASM simulation. We also examine the impacts of the improved EASM precipitation on other physical process. Our results suggest similar model sensitivity and values of optimized parameters across years with different EASM intensities. By applying the optimal parameters, the simulated precipitation and surface energy features are generally improved. The parameters related to downdraft, entrainment coefficients and CAPE consumption time (CCT) can most sensitively affect the precipitation and atmospheric features. Larger downdraft coefficient or CCT decrease the heavy rainfall frequency, while larger entrainment coefficient delays the convection development but build up more potential for heavy rainfall events, causing a possible northward shift of rainfall distribution. The CCT is the most sensitive parameter over wet region and the downdraft parameter plays more important roles over drier northern region. Long-term simulations confirm that by
\end{abstract}

\footnotetext{
B. Yang $\cdot$ Y. Zhang $(\bowtie) \cdot$ A. Huang

School of Atmospheric Sciences, Nanjing University,

Nanjing 210093, China

e-mail: yczhang@nju.edu.cn

Y. Qian · H. Yan

Pacific Northwest National Laboratory, Richland, WA, USA

H. Yan

School of Atmospheric Sciences, Lanzhou University,

Lanzhou, China
}

using the optimized parameters the precipitation distributions are better simulated in both weak and strong EASM years. Due to more reasonable simulated precipitation condensational heating, the monsoon circulations are also improved. By using the optimized parameters the biases in the retreating (beginning) of Mei-yu (northern China rainfall) simulated by the standard WRF model are evidently reduced and the seasonal and sub-seasonal variations of the monsoon precipitation are remarkably improved.

Keywords Parameter calibration - The East Asian summer monsoon precipitation - Convection scheme . WRF model simulation

\section{Introduction}

During warm seasons, abundant rainfall over most areas of China is brought by the East Asian summer monsoon (EASM), which is a hybrid of tropical and subtropical monsoon with variations at different time-scales (Tao and Chen 1987; Ye and Huang 1996; Ding 1992; Ding and Chan 2005). Currently, the modeling of the EASM and its associated precipitation is still a challenging task in the climate model community because many external factors could potentially modulate the monsoon intensity and evolution (Liu et al. 2002; Zhou and Li 2002; Cheng et al. 2008; Kosaka et al. 2011; Chang et al. 2013). Even with regional climate models (RCMs) driven by high-quality lateral boundary conditions, the simulation of the EASM precipitation may still be problematic because of the uncertainties within the physical schemes, especially those related to precipitation characterized by large spatial and temporal discontinuity (Liu et al. 1996; Wang et al. 2000b; 
Yhang and Hong 2008; Qian and Leung 2007; Zou and Zhou 2011).

Distinct dynamics over the EASM region are induced by the complex terrain, remarkable land-ocean contrast and strong interaction between tropical and mid-latitude systems (Lau et al. 2000; Liu et al. 2002; Enomoto et al. 2003; Chang et al. 2013). Evident seasonal propagation from southern to northern China and significant inter-annual variability, which are unique characteristics of the EASM precipitation, are largely affected by tropical sea surface temperature (SST), Eurasia and Tibetan Plateau snow cover, and so on (Wang et al. 2000a; Ding and Chan 2005; Hsu and Lin 2007; Wang et al. 2008a; Cheng et al. 2008; Qian et al. 2011). Large-scale forcing is important for rainfall distribution, while precipitation feedback can in turn affect the circulation to some extent. For example, Lu and Lin (2009) suggested that subtropical precipitation could influence the background circulations and may be crucial for maintaining the meridional teleconnection. A recent study by Sampe and Xie (2010) also pointed out that the Mei-yu condensational heating over the Yangtze River Basin (YRB) region could enhance the upward motion and increase warm advection downstream over the Baiu area.

Because of the complicated interactions internally or externally, the simulations of the EASM system with global circulation models (GCMs) are very difficult (Arai and Kimoto 2007; Zhang et al. 2008; Chen et al. 2010). The missing of regional details may also limit the ability of GCMs (Leung et al. 2003). Recently, the Regional Climate Model Inter-comparison Project (RMIP) for Asia has been established to investigate the modeling of Asian climate with an ensemble of RCMs driven by near-observed boundary conditions (Fu et al. 2005). However, due to the incomplete physical processes, current RCM results still have large bias, especially for precipitation. Lee and Suh (2000) found that the simulated monsoon rain-belt by RegCM2 was shifted northward by $2-3^{\circ}$ with respect to observation. Wang et al. (2003) applied a highly resolved RCM to simulate the 1998 severe flood event over China, showing that the model could produce the double Mei-yu periods but displaced the second rain-belt $2^{\circ}$ latitude to the north. Park et al. (2008) also showed in RegCM3 the precipitation was underestimated over Korean and nearby oceans but overestimated to the south and north. Such model discrepancy could certainly affect the simulated features of seasonal and inter-annual variations of the monsoon precipitation featured by significant meridional oscillations. For example, Ding et al. (2006) found the second northward jump of rain-belt in the RegCM2 (modified version by the National Climate Center, China Meteorological Administration) was earlier than observed, resulting in a longer (shorter) rainy season over northern China (the YRB region). The atmosphere and land/ocean properties will also be influenced (Leung et al. 1999; Qian and Leung 2007; Zou and Zhou 2011; Yang et al. 2012; Fang et al. 2013).

Many processes are responsible for the generation of precipitation, e.g. convection, radiation, planetary boundary layer (PBL) mixing, land surface processes, and so on (Leung et al. 1999, 2004; Ding et al. 2006; Cha et al. 2008; Trier et al. 2008; Yang et al. 2012). Better combination of physical schemes could be obtained for precipitation simulation but may yield unrealistic physical state through compensating errors between different schemes. Among them, cumulus convective process is closely linked to the precipitation by affecting the generation of precipitation directly and indirectly through influencing the upper-layer hydrometer condition and circulation (Arakawa and Schubert 1974; Emanuel et al. 1994; Arakawa 2004; Song and Zhang 2011). For current climate modeling at relatively low horizontal resolution (e.g. coarser than several $\mathrm{km}$ ), sub-grid cumulus parameterization is needed, inducing additional uncertainty sources to the already complex climate modeling (Janjić 1994; Zhang and McFarlane 1995; Emanuel and Zivkovic-Rothman 1999; Gregory et al. 2000; Grell and Devenyi 2002; Wu 2012). Yu et al. (2011) compared the simulated summer monsoon precipitation over China by three different convection schemes in the Weather Research and Forecasting (WRF) model, suggesting that all the schemes tended to overestimate the precipitation over southern and northern China but underestimate the precipitation over the YRB region. The comparison indicated the Grell-Devenyi scheme gave the best results among the three schemes.

The physical parameterization schemes including convection scheme always contain numerous parameters, whose values are usually arbitrarily determined based on the limited measurements or empirical relationships (Kain 2004; Müller and Scherer 2005; Done et al. 2006; Bechtold et al. 2008; Berner et al. 2012). Therefore, comparing different convection schemes directly could be difficult as one may not be able to determine whether the diversities are from the differences of scheme structures or system biases resulting from uncertain parameters. Leung et al. (1999) stated that inter-comparison of model skills would be more meaningful if each model was tuned to perform better. Moreover, the parameter calibration process can help investigate the impacts of process-level parameters on the model results and understand the potential for improving a scheme at a given structure. Yang et al. (2012) applied an importance-sampling algorithm, i.e. Multiple Very Fast Simulated Annealing (MVFSA, Ingber 1989; Jackson et al. 2004) to quantify the uncertainties of five key parameters in the Kain-Fritsch (KF) convection scheme in the WRF RCM over the US South Great Plain (SGP) region. Their results showed that the model performance 
was most sensitive to a few parameters in the KF scheme. When applying the identified optimal parameters, the simulated precipitation magnitude and pattern as well as the rain-rate spectrum were remarkably improved. Following Yang et al. (2012), Yan et al. (2014) further examined the calibration processes of parameters with various model spatial resolutions and over two different climate regimes. They found that in spite of differences in the precipitation climatology, model performance exhibited similar dependence on the input parameters over the two regimes.

Previous calibration studies (i.e. Yang et al. 2012; Yan et al. 2014) were mainly focusing on the mean precipitation during a selected extreme wet month. However, given the distinct features of the EASM precipitation with multiple rain-belt advances, question arises whether the calibrated results can induce positive impacts when applied to longterm simulations involving more processes at seasonal and sub-seasonal scales. Specifically, it is not clear to what extent will the calibrated parameters improve the simulated monsoon precipitation in terms of not only the mean magnitude, but also the south-north gradient and seasonal propagating features. Whether the calibration process of convective parameters will be similar across years with varying EASM intensities is also an important question for the parameterization development and EASM climate modeling.

To address the above questions, in this study we apply the MVFSA approach to investigate the impacts of several key parameters in the KF convection scheme in the WRF RCM (Skamarock et al. 2008; Yang et al. 2012) on the simulated EASM precipitation, especially the Mei-yu precipitation over the YRB region, in three years with strong, normal and weak EASM intensities, respectively. The response of atmospheric circulation and precipitation evolutions to the parameters are also explored with long-term model integrations.

This paper is organized as follows. The observations, MVFSA sampling algorithm, selected convective parameters and model configuration are introduced in Sect. 2. Section 3 presents the optimization results, model sensitivity, and the impacts of the optimized parameters on the simulated circulation and precipitation features. The Sect. 4 are given in the last section.

\section{Dataset, methodology and experiments}

\subsection{Observational data}

The rain gauge observations (daily) at 756 stations in China acquired from the National Meteorological Information
Center of China Meteorological Administration are applied to constrain the calibration process. The National Centers for Environment Prediction (NCEP) operational global Final (FNL) analyses data at $1.0^{\circ} \times 1.0^{\circ}$ grid spacing and 6-h interval from 2000 to 2009 are used to provide initial and boundary conditions for model integration. These two datasets, as well as the surface flux data (i.e. net shortwave radiative flux, sensible and latent heat fluxes) used or produced by the global land data assimilation system (GLDAS) with the Noah land surface model, are used for model evaluations (Chen and Dudhia 2001; Rodell et al. 2004). Monthly wind products from the NCEP reanalysis at 2.5-degree are applied for the calculation of the EASM index.

\subsection{Optimization algorithm}

Following Yang et al. (2012), the model performance is evaluated by a dimensionless skill score $E$ defined as:

$E=\sum_{i=1}^{N} \frac{1}{2 N}\left[\left(\mathbf{d}_{\mathrm{obs}}-\mathbf{g}\right)^{T} \times \mathbf{C}^{-1}\left(\mathbf{d}_{\mathrm{obs}}-\mathbf{g}\right)\right]_{i}$,

where $N$ refers to different variables. $\mathbf{d}_{\text {obs }}$ and $\mathbf{g}$ are observations and simulations, respectively. $\mathbf{C}^{-1}$ is the inverse of the data covariance matrix, which could include a weight coefficient for different variables and spatially or temporally correlations among model biases at different points. In this study, only the precipitation observation is used for evaluation. We assume equal weight at each grid point and spatially or temporally uncorrelated model biases, i.e., the data covariance matrix $\mathbf{C}^{-1}$ only contains nonzero elements along the diagonal, so $E$ is simplified as:

$E=\left[\sum_{k=1}^{K} \sum_{i=1}^{I} \sum_{j=1}^{J}\left(d_{\mathrm{obs}, \mathrm{j} \mathrm{k}}-g_{i j k}\right)^{2}\right] /(I \times J \times K)$,

where $i, j$ are indexes for horizontal grid points in the model domain, and $k$ represents the day series. Thus, the skill score $E$ is basically based on the mean square error of the simulated daily precipitation against observation.

The identical sampling approach MVFSA used by Yang et al. (2012) is applied in this study. With a stochasticimportance sampling technique, the Very Fast Simulated Annealing (VFSA) algorithm can efficiently sample points toward the optimal values minimizing the model bias (Ingber 1989; Jackson et al. 2004). Usually more than one extreme point (minimum or maximum) exists within the parameter space, which could trap the VFSA procedure to some local minimums/maximums. The MVFSA (i.e. Multiple-VFSA) is an approach repeating the VFSA several times with different initial starting values so as to reduce the possibility of local trapping and help identify the 
global minimum (Jackson et al. 2008; Villagran et al. 2008). Detailed descriptions and operations of MVFSA can be referred to Jackson et al. $(2004,2008)$ and Yang et al. (2012).

In this study, we conduct the VFSA three times (i.e. three chains) and each chain contains 50 iterations of WRF model simulation (i.e. parameters were perturbed 50 times). Therefore, a total of 150 simulations with different parameter sets are derived, which is consistent with Yang et al. (2012).

\subsection{Model and selected convective parameters}

The WRF model version 3.2.1 (referred to as WRF for short, Skamarock et al. 2008) is applied with grid and subgrid moisture processes parameterized by the Morrison 2-moment microphysics scheme (Morrison et al. 2005) and KF convection Scheme (Kain 2004), respectively. The Noah land surface model (Chen and Dudhia 2001) and Mellor-Yamada-Janjić (Janjić 2002) PBL turbulence scheme are also used. Short-wave and long-wave radiative processes are represented by the RRTMG schemes (Rapid Radiative Transfer Model for GCMs, Mlawer et al. 1997; Pincus et al. 2003).

The KF convection scheme is a mass flux type parameterization commonly used in many meso-scale models (Kain and Fritsch 1990; Kain 2004). It starts by searching for the updraft source layer (USL) that can potentially trigger convective updraft with a Lagrangian parcel method (Simpson and Wiggert 1969; Kreitzberg and Perkey 1976). Entrainment and detrainment tend to cause air mass exchange between updraft and environmental air, and downdraft is induced by precipitation and fueled by rain evaporation. Once the convection is triggered, either deep or shallow convection is parameterized depending on the vertical extent of the updraft. Different closure assumptions are used for deep and shallow convections, i.e. the strength of deep convection is dependent on the consumption rate of CAPE (i.e. convective available potential energy) within the USL, while the shallow convection strength is calculated based on the turbulent kinetic energy (TKE) in the sub-cloud layer. For more detailed descriptions of the KF scheme please refer to Kain and Fritsch (1990), Bechtold et al. (2001) and Kain (2004).

Same as Yang et al. (2012), five important parameters related to the downdraft flux coefficient $\left(P_{d}\right)$, entrainment flux coefficient $\left(P_{e}\right)$, downdraft starting height $\left(P_{h}\right)$, TKE $\left(P_{t}\right)$, and CAPE consumption time $\left(\mathrm{CCT}, P_{c}\right)$ within the KF scheme are studied here. The descriptions, default values and perturbed ranges of the five selected parameters are listed in Table 1.
Table 1 Descriptions, default values and perturbed ranges of the five selected parameters in the KF convection scheme

\begin{tabular}{|c|c|c|c|}
\hline Parameter & Default & Range & Description (unit) \\
\hline$P_{d}$ & 0 & -1 to 1 & $\begin{array}{l}\text { Coefficient related to } \\
\text { downdraft mass flux rate }(-)\end{array}$ \\
\hline$P_{e}$ & 0 & -1 to 1 & $\begin{array}{l}\text { Coefficient related to } \\
\text { entrainment mass flux rate }(-)\end{array}$ \\
\hline$P_{h}$ & 150 & 50 to 350 & $\begin{array}{l}\text { Starting height of downdraft } \\
\text { above USL }(\mathrm{hPa})\end{array}$ \\
\hline$P_{t}$ & 5 & 3 to 12 & $\begin{array}{l}\text { Maximum TKE in sub-cloud } \\
\text { layer }\left(\mathrm{m}^{2} \mathrm{~s}^{-2}\right)\end{array}$ \\
\hline$P c$ & 2700 & 900 to 7200 & $\begin{array}{l}\text { Average consumption time } \\
\text { of CAPE (s) }\end{array}$ \\
\hline
\end{tabular}

\subsection{Numerical experiment design}

As the requirement of huge computational resources, the simulations for identifying optimal parameters are firstly conducted only during the climatological Mei-yu period from 16 Jun to $15 \mathrm{Jul}$ for selected years with strong, normal and weak EASM intensities, respectively. Two additional 10-summer simulations with the default and optimal parameters are performed to investigate the impact of parameter calibration on the simulation of the monsoon precipitation evolutions.

The EASM precipitation is featured by significant seasonal advances of rain-band from southern to northern China. Traditionally, above-normal northern China rainfall accompanied by a deficient YRB Mei-yu indicates a strong EASM when the southerlies penetrate more northward inland (Ding 1994). However, Wang et al. (2008b) pointed out that the inter-annual variability and seasonal propagation of the EASM are two modes with different fundamental causes, and compared with the northern China rainfall, the Mei-yu can better represent the inter-annual variability of the large scale EASM features. As a result, they reversed the traditional meaning of monsoon strength by defining a strong Mei-yu as a strong monsoon year. Here we apply a simplified shear vorticity index, i.e. $850 \mathrm{hPa}$ zonal wind in $\left(22.5^{\circ}-32.5^{\circ} \mathrm{N}, 110^{\circ}-140^{\circ} \mathrm{E}\right)$ minus that in $\left(5^{\circ}-15^{\circ} \mathrm{N}, 90^{\circ}-130^{\circ} \mathrm{E}\right)$, to represent the inter-annual variability of the EASM (Wang and Fan 1999; Wang et al. (2008b). The year-to-year (1980-2009) variations of the EASM index and summer mean precipitation over the YRB region (depicted in Fig. 2) are shown in Fig. 1, from which a clear positive correlation is found between the EASM index and Mei-yu precipitation for most years. Considering the potential impacts of the EASM intensity on parameter optimization, we select 3 years with respectively strong, normal and weak EASMs from 2000 to 2009, during which similar decadal climate backgrounds are 
expected and the FNL reanalysis for driving the WRF are available. Figure 1a shows that from 2000 to 2009, weak (strong) EASMs occur in 2001 and 2004 (2007 and 2008), and monsoon intensities are moderate in 2000 and 2005. Meanwhile, positive and negative Mei-yu anomalies are found in 2001/2006 and 2007/2008, respectively. During 2002 and 2005, the Mei-yu precipitation is relatively normal. Based on these two criteria, we select the years of 2001 and 2005 as weak and normal EASM cases, respectively. The year of 2007 is chosen as strong EASM case because in 2007, more precipitation events occur during the climatological Mei-yu period than in 2008. The spatial distributions of precipitation for the three selected years are presented later (Sect. 3.1, Fig. 4).

The model domain for parameter optimization is located within $105^{\circ} \mathrm{E}-125^{\circ} \mathrm{E}$ and $21^{\circ} \mathrm{N}-41^{\circ} \mathrm{N}$ at $25 \mathrm{~km}$ grid spacing (small dashed box in Fig. 2, same size and horizontal resolution as the SGP domain in Yang et al. 2012). The YRB region is at the center of the model domain. As the fast increasing of errors in the simulated large-scale meteorological field, atmospheric conditions are reinitiated every 2 days in the optimization experiment from 16 Jun to $15 \mathrm{Jul}$, effectively isolating the impacts of convective scheme on precipitation from those potentially induced by the circulation biases. To simulate more realistic land-air interactions, soil moisture and temperature are consecutively transferred during the integration period. The

(a) EASM Index

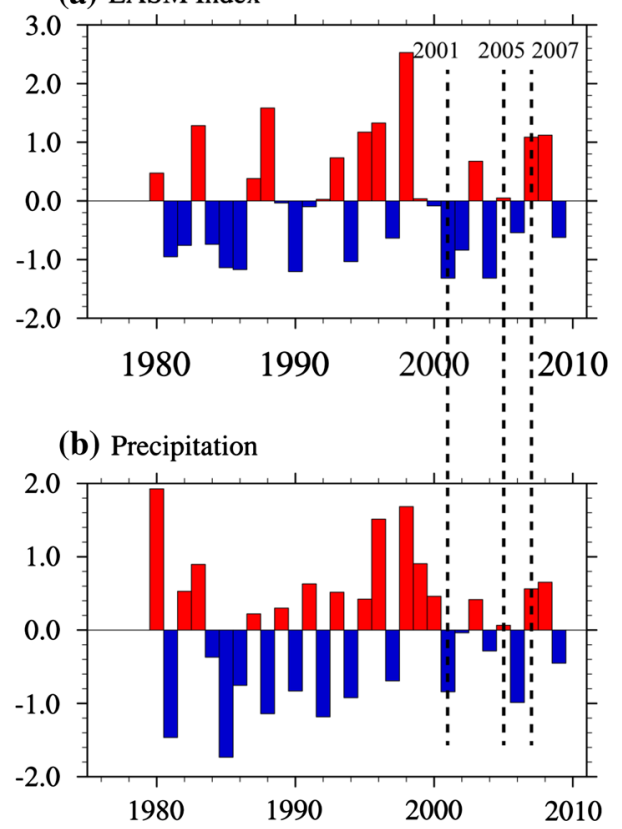

Fig. 1 Year-to-year variations of the standardized a EASM index (NECP reanalysis) and b JJA Mei-yu precipitation (station observation) from 1980 to 2009. The years of 2001, 2005 and 2007 featured by weak, normal and strong EASM intensities are selected for optimization experiments

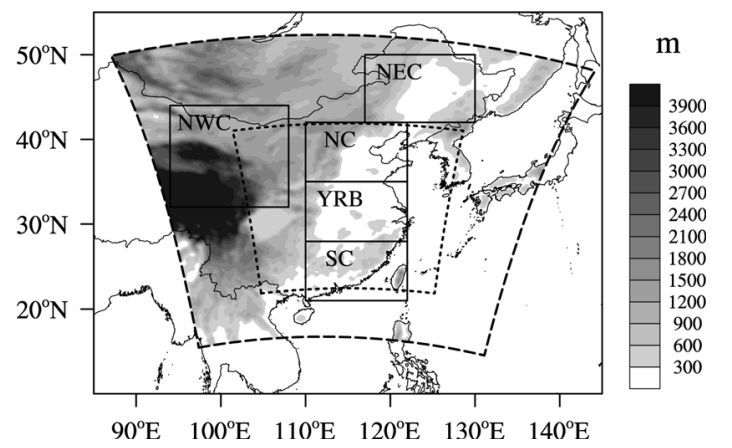

Fig. 2 WRF model domains for parameter calibration (smaller dashed box) and validation (lager dashed box). Solid boxes denoted the 5 sub-regions of Southern China $(S C)$, the Yangtze River Basin $(Y R B)$, Northern China $(N C)$, Northeastern China $(N E C)$ and Northwestern China $(N W C)$, respectively. Shades indicate the terrain

1-month WRF simulations (i.e. during the Mei-yu period) are conducted repeatedly one by one with perturbed parameters generated by the MVFSA procedure that converges to the optimal parameters.

Two additional sets of 10-summer (2000-2009) simulations are also conducted with the default and optimized parameters identified from the optimization approach. To better consider the EASM precipitation feedback on circulation, the WRF is run continuously (i.e. free-run) instead of using the re-initiation mode from May to Aug for each year. A relatively larger domain covering most areas of the EASM region (around $95^{\circ} \mathrm{E}-135^{\circ} \mathrm{E}$ and $15^{\circ} \mathrm{N}-50^{\circ} \mathrm{N}$, larger dashed box in Fig. 2) is used, with the purpose to give more free interactions between precipitation and large-scale circulation but also exclude the impacts of other external factors such as the convection over Maritime Continent and India, which are also sensitive to the selected parameters and have strong effects on the EASM evolution.

\section{Results}

In this section, the identified optimal parameters and derived results as well as the model sensitivities are analyzed based on the 150 one-month simulations with perturbed parameters (Sect. 2.2). The impacts of parameter calibration on the simulated monsoon circulation and precipitation evolutions are also investigated based on the 10 -summer simulations with the default and optimized parameters.

\subsection{Optimized results}

For each year, a total of 150 one-month simulations are conducted. The responses of model performance (indicated by $E$, Sect. 2.2) to the five convective parameters during 

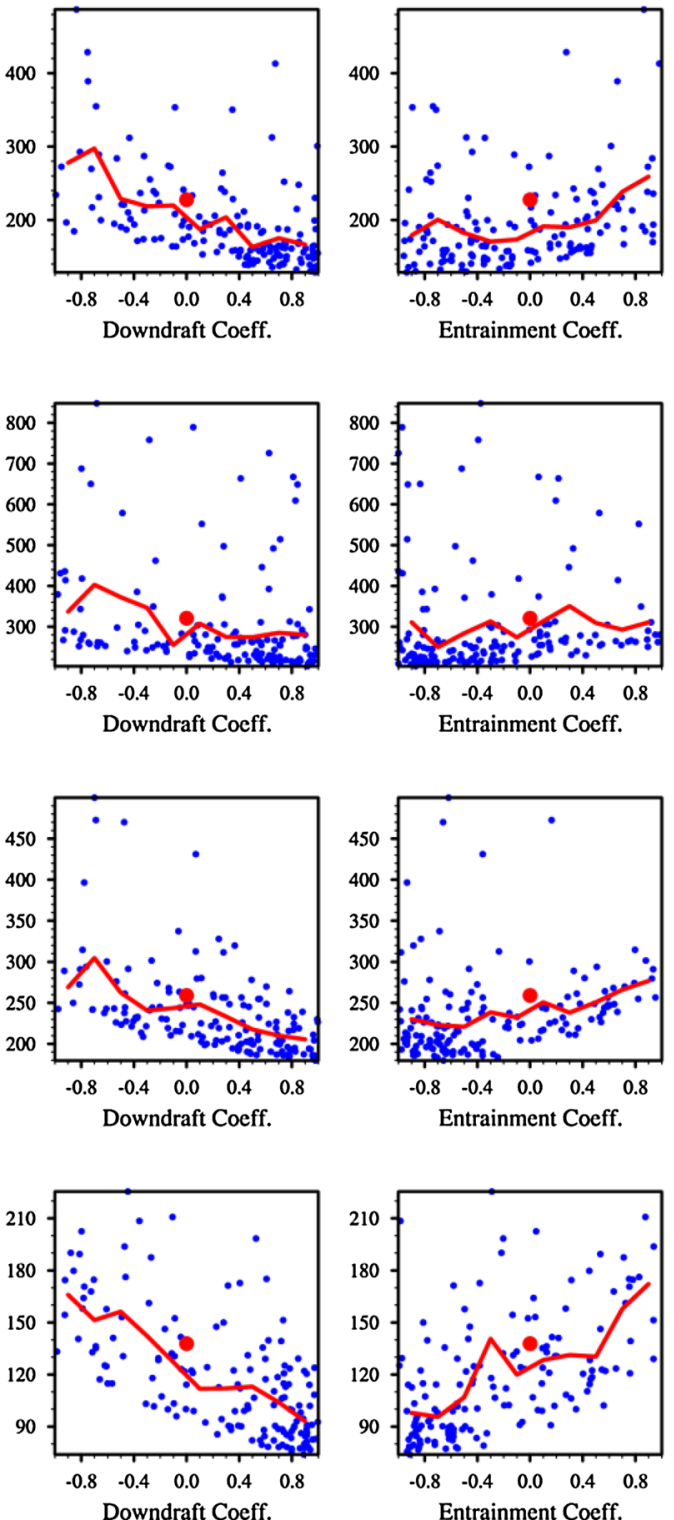

(a) 2001
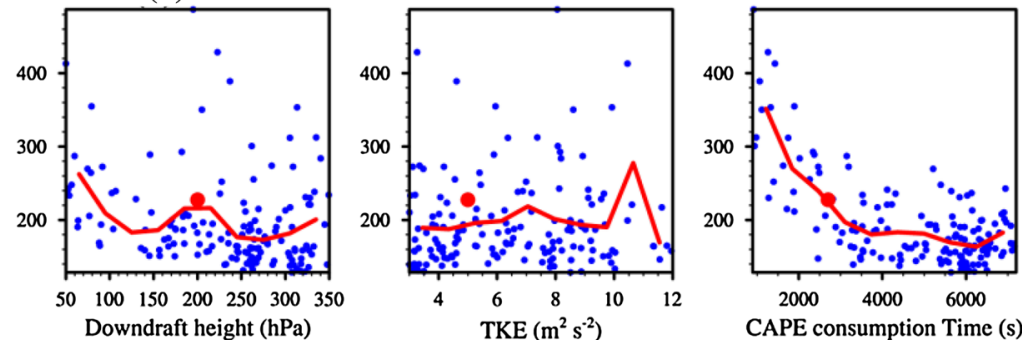

(b) 2005
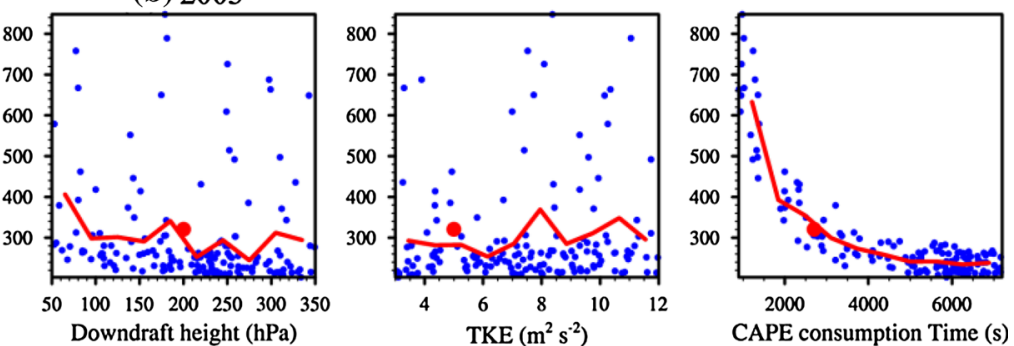

(c) 2007
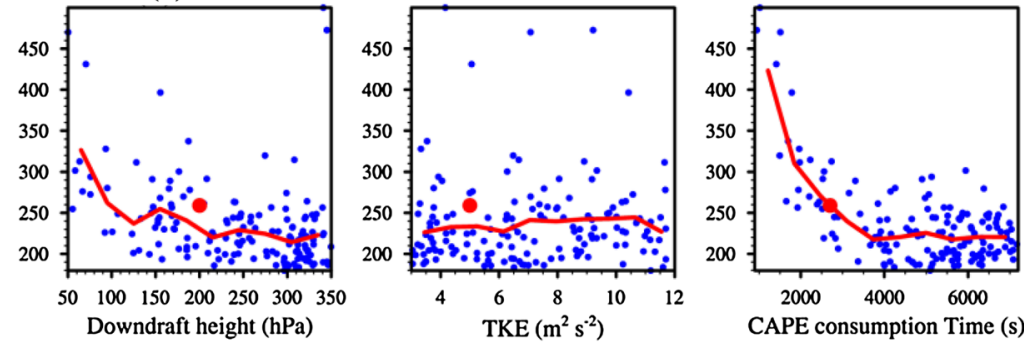

(d) SGP
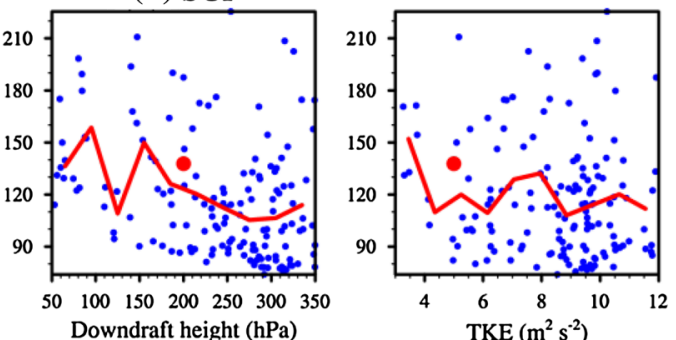

Fig. 3 The responses of model performance (quantified as $E$, Y-axis) to the five input parameters (X-axis) for the cases of a 2001, b 2005, c 2007 and d SGP, respectively. Red curves represent the average

the 3 years with respectively weak, normal and strong EASM intensities are shown in Fig. 3, together with the SGP results by Yang et al. (2012) for comparison. It shows that for all cases with different EASM intensities or over different regions, the dependences of model skills on parameters are similar, e.g. the parameter of CCT $\left(P_{c}\right)$ is the most important for the model behaviors. Large dependences of model performance on the downdraft $\left(P_{d}\right)$ and entrainment $\left(P_{e}\right)$ coefficients are also evident for all cases except in 2005, where $P_{c}$ is the dominant parameter for model response. Actually, apparent relationships between $E$ and $P_{d} / P_{e}$ can be found if the experiments with values of $E$ at each tenth bin within the parameter space for each parameter. The standard WRF results are denoted by red dots

small $P_{c}(<2000 s)$ are excluded in 2005. Table 2 presents the optimal parameters identified through the MVFSA procedure for the 3 years. It is indicated that the calibrated values are close during the 3 years for all the parameters except for the TKE parameter $\left(P_{t}\right)$ with weak importance (Fig. 3). The above results suggest that the calibration processes constrained by the observed precipitation are similar across regions or years with different EASM intensities to some extent (Yan et al. 2014).

The spatial distributions of precipitation (from 16 Jun to $15 \mathrm{Jul}$ ) observed and simulated with the default and optimized parameters (Table 2) are presented in Fig. 4 for each 
year. As shown in Fig. 1, the years of 2001, 2005 and 2007 are characterized by weak, normal and strong Mei-yu precipitation over the YRB region, respectively. When using the standard WRF with the default KF parameters, the precipitation are all overestimated during the selected years, which is consistent with our previous studies over the SGP region (Yang et al. 2012; Yan et al. 2014). Such positive biases are remarkably reduced by applying the optimized parameters identified through the MVFSA procedure. The skill scores $E$ decrease from 227 to 131, 321 to 203, and 259 to 180 in 2001, 2005 and 2007, respectively (see Table 2). Moreover, the simulated precipitation patterns indicated by $R$ (i.e. spatial correlation between the simulated and observed precipitation, Table 2) are also improved for all the 3 years. However, the rainfalls over Sichuan area (around $30^{\circ} \mathrm{N}$ and $107^{\circ} \mathrm{E}$ ) are always

Table 2 The default and optimized values of the five KF parameters and the corresponding skill scores in 3 years with different EASM intensities

\begin{tabular}{llllllll}
\hline & $P_{d}$ & $P_{e}$ & $P_{h}$ & $P_{t}$ & $P_{c}$ & $E / E(\operatorname{def})$ & - \\
\hline Def & 0 & 0 & 150 & 5 & 2700 & - \\
Opt 2001 & 0.96 & -0.52 & 252 & 3.3 & 6,501 & $131 / 227$ \\
Opt 2005 & 0.92 & -0.87 & 333 & 3.1 & 5,869 & $203 / 321$ & $0.46 / 0.45$ \\
Opt 2007 & 0.98 & -0.66 & 296 & 11.2 & 5,094 & $0.47 / 0.45$ \\
\hline
\end{tabular}

$R$ represents the spatial correlation between the observed and simulated precipitation

(a) OBS

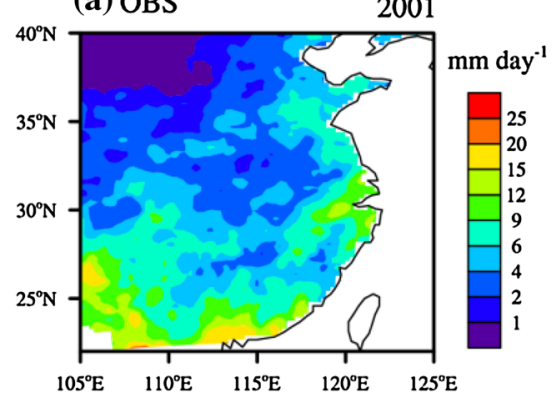

(d) DEF

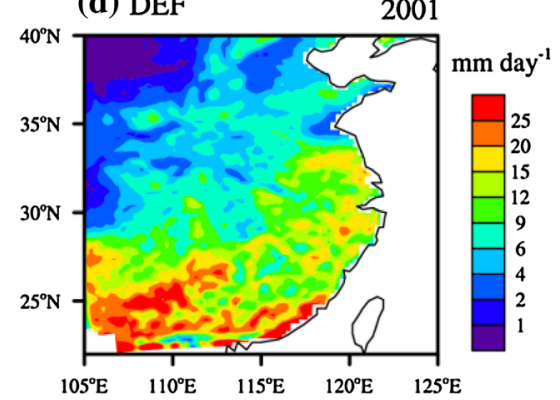

(g) OPT

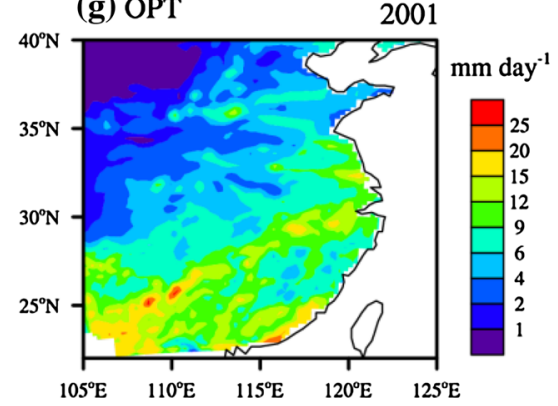

(b) OBS

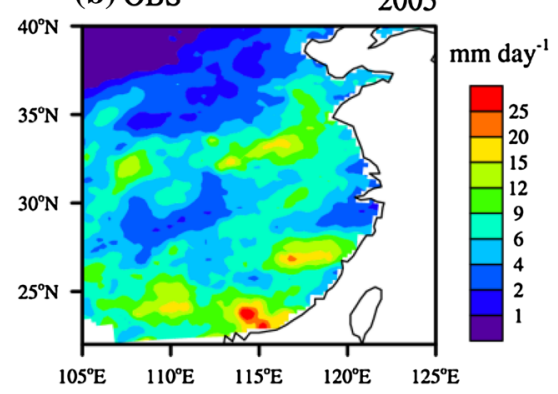

(e) DEF

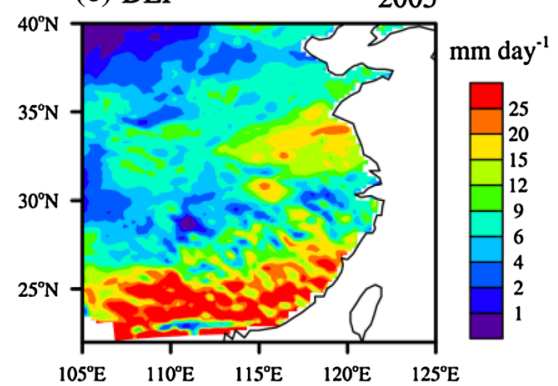

(h) OPT

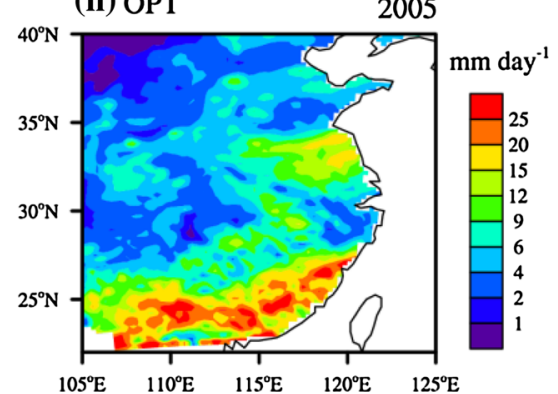

(c) OBS

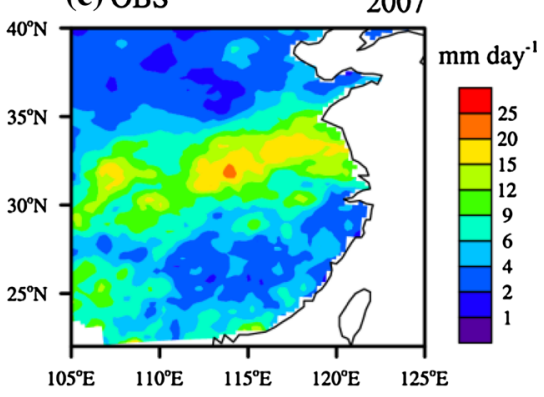

(f) $\mathrm{DEF}$

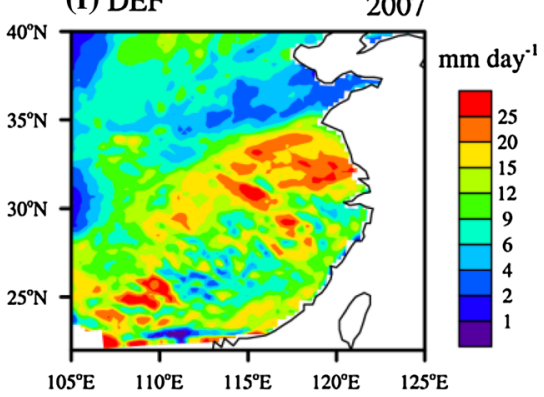

(i) OPT

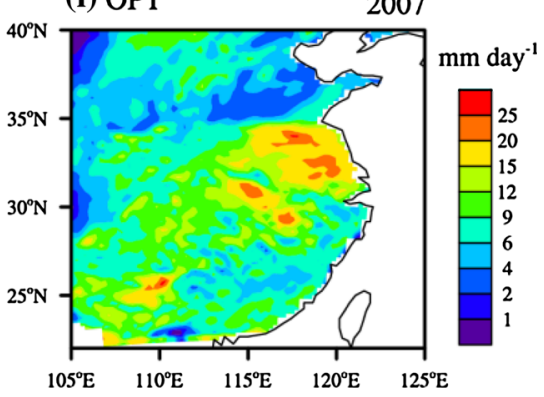

Fig. 4 Spatial distributions of precipitation (during Mei-yu period from 16 Jun to $15 \mathrm{Jul}$ ) in the a-c observation, $\mathbf{d}-\mathbf{f}$ standard and $\mathbf{g}-\mathbf{i}$ optimized WRF simulations, for (left) 2001, (middle) 2005 and (right) 2007, respectively 
(a) Net shortwave GLDAS

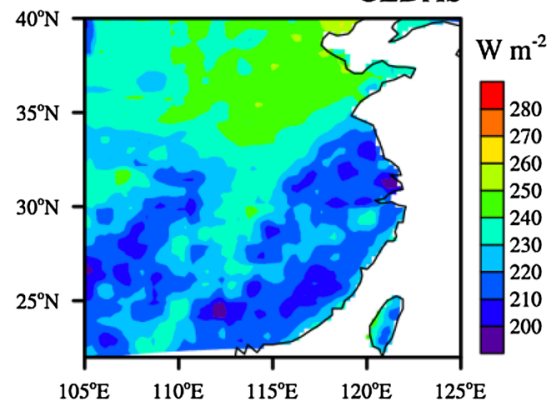

(d) Net shortwave

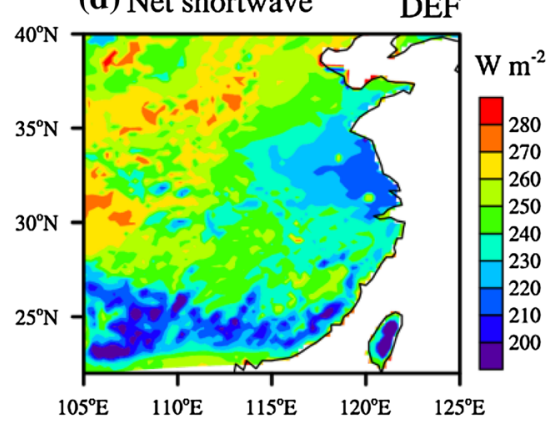

(g) Net shortwave

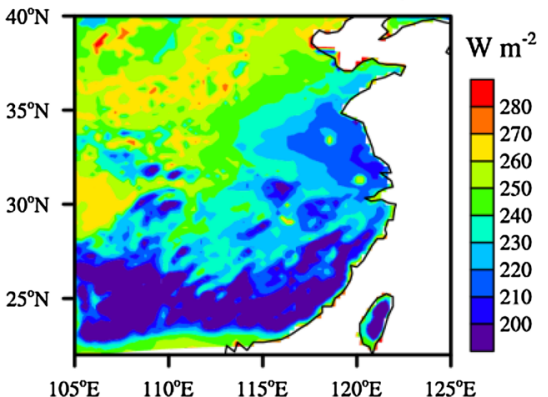

(b) Sensible heat GLDAS

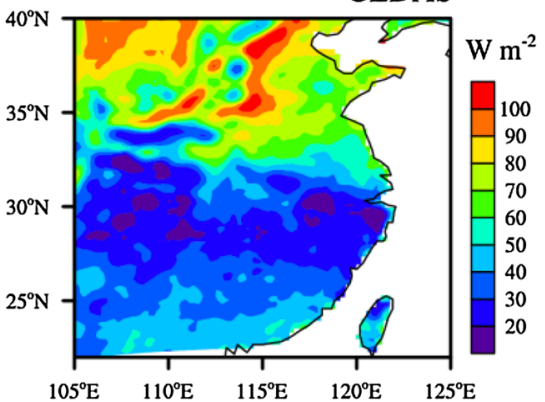

(e) Sensible heat

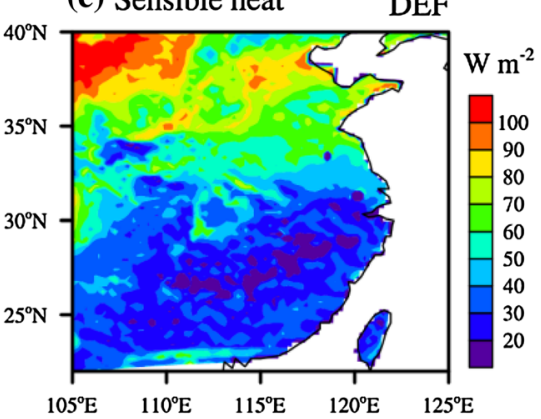

(h) Sensible heat

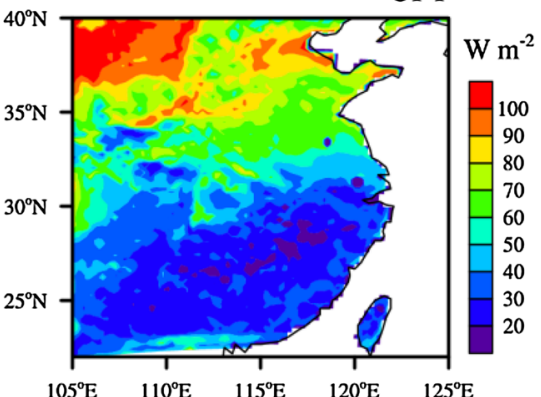

(c) Latent heat

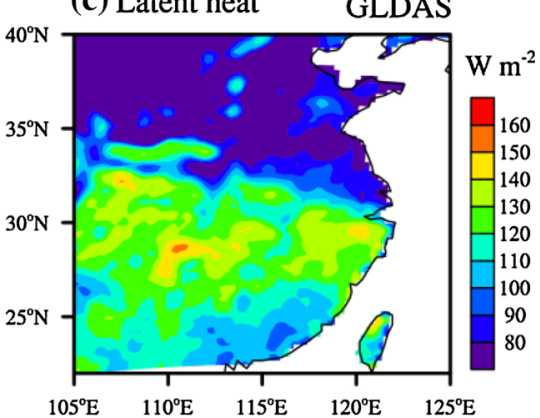

(f) Latent heat

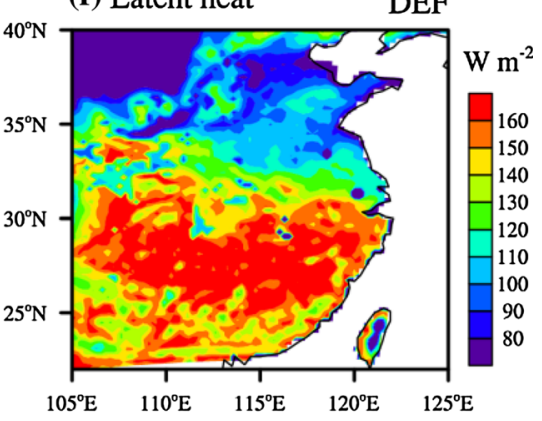

(i) Latent heat

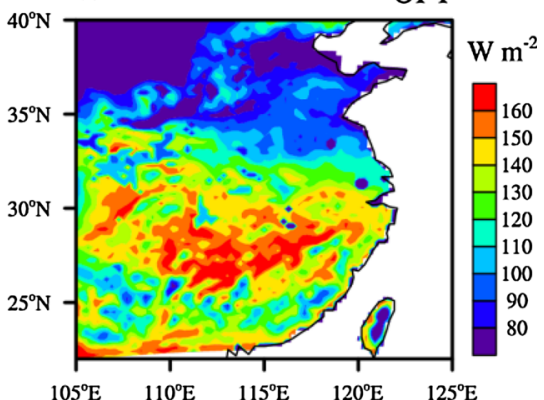

Fig. 5 Spatial distributions of (left) net shortwave radiative fluxes, (middle) sensible and (right) latent heat fluxes at surface (averaged during Mei-yu periods in 3 years) from the a-c GLDAS, $\mathbf{d}-\mathbf{f}$ standard and $\mathbf{g}-\mathbf{i}$ optimized WRF simulations, respectively

underestimated in each year, which is probably because of the poor performance of the WRF in simulating the nocturnal precipitation there (figure not shown).

As the surface energy budgets and hydrological features are closely connected with the precipitation and associated cloud properties, the spatial features of the net shortwave radiative flux, sensible and latent heat fluxes (3-year average) simulated with the default and optimized parameters are also compared against the GLDAS results in Fig. 5. It shows the standard WRF overestimates the net shortwave radiation over most areas. By using the optimized parameters, the mean magnitude and spatial pattern show better agreements with the GLDAS except over southern China with underestimated fluxes. The overestimated latent heat fluxes in the standard WRF (Fig. 5f) are also remarkably reduced by applying the optimized parameters due to less downward solar radiation and less precipitation (Fig. 4). Contrastingly, the simulated sensible heat fluxes are less affected and only slightly improved over eastern China probably because of the opposite effects of less solar radiation and precipitation at surface. As only the convective parameters are tuned, it is likely that the changed surface flux is a response to the varied precipitation at surface and cloud condition in the atmosphere (Sect. 3.2). Interactively, the changed surface fluxes will further affect the precipitation through influencing the local boundary layer structure and atmospheric vertical profile and circulation.

\subsection{Model sensitivity to different parameters}

As discussed in Yang et al. (2012), the parameters of downdraft, entrainment coefficients and CCT are the three most important parameters for the simulated domain- 
(a) Potential temperature

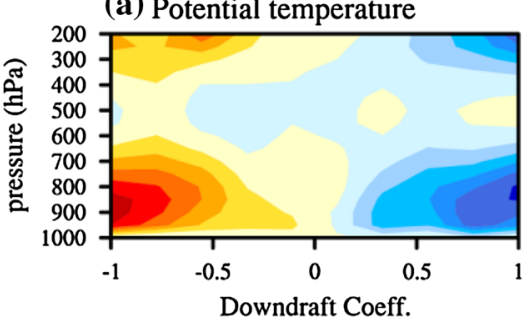

(d) Specific Humidity

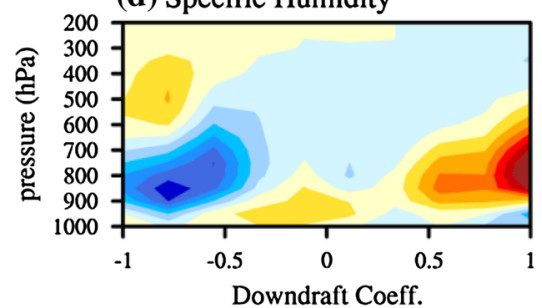

(g) Moist Static Energy

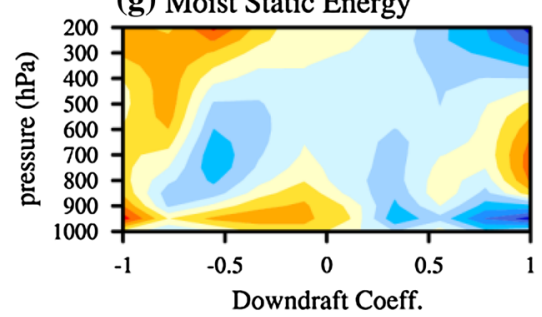

(j) Cloud content

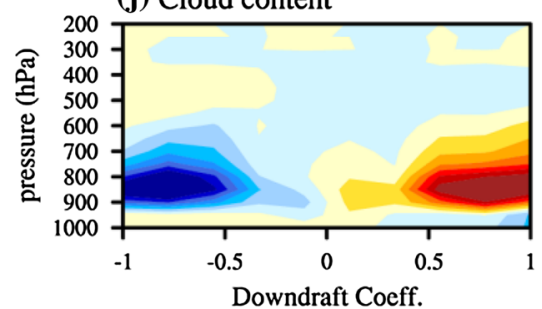

(b) Potential temperature

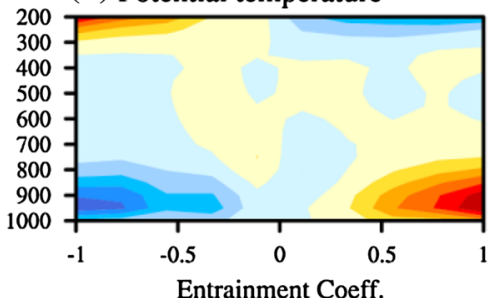

(e) Specific Humidity

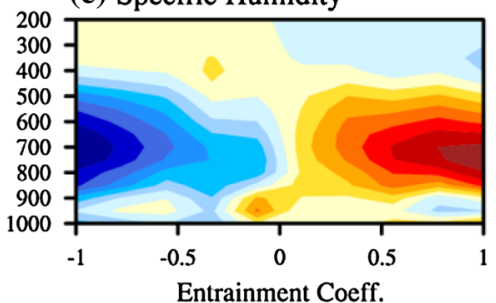

(h) Moist Static Energy

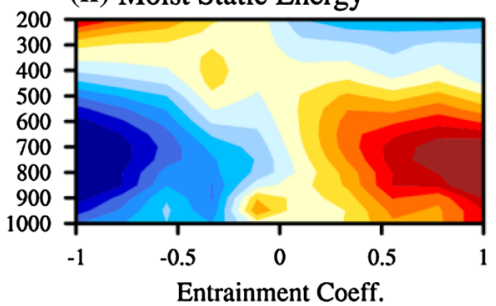

(k) Cloud content

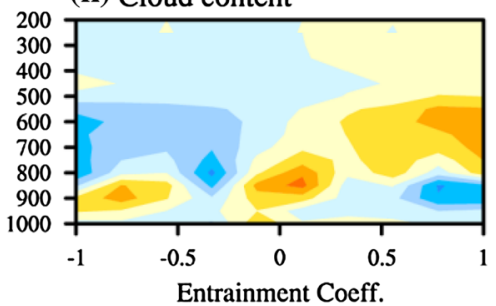

(c) Potential temperature

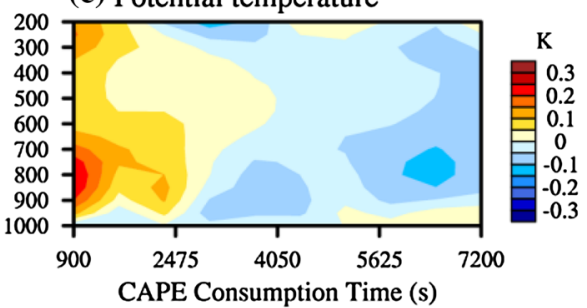

(f) Specific Humidity

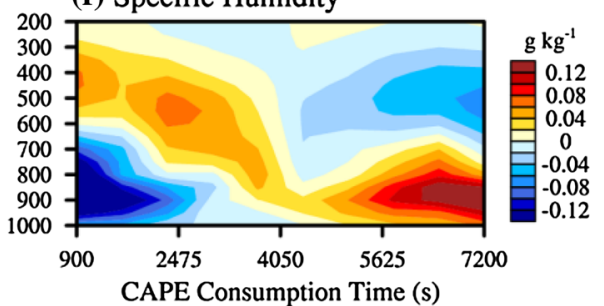

(i) Moist Static Energy

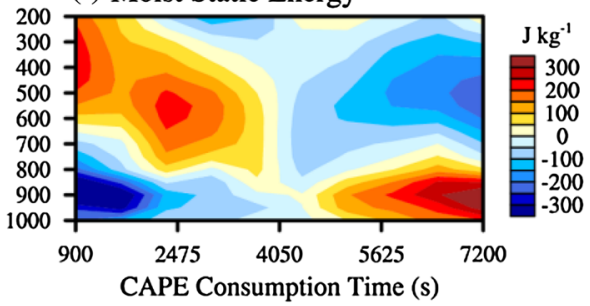

(l) Cloud content

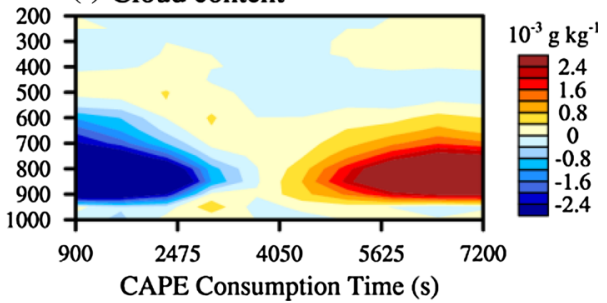

Fig. 6 Responses of vertical profiles (averaged over $23^{\circ}-38^{\circ} \mathrm{N}$, $107^{\circ}-122^{\circ} \mathrm{E}$ ) for $\mathbf{a}-\mathbf{c}$ potential temperature, $\mathbf{d}-\mathbf{f}$ specific humidity, $\mathbf{g}-\mathbf{i}$ moist static energy and $\mathbf{j}-\mathbf{l}$ cloud content to (X-axis) the parameters of (left) downdraft $\left(P_{d}\right)$, (middle) entrainment $\left(P_{e}\right)$ and (right) CAPE consumption time $\left(P_{c}\right)$ in 2007, respectively. All profiles are given as anomalies at each tenth bin within the parameter space, i.e. subtracted by the average of the 10 bins average precipitation and overall model system over the SGP region. Stronger downdraft can increase the rainwater evaporation within the downdraft and decrease the surface precipitation, while larger entrainment flux enhances the mixing between updraft and environment, suppressing the extension of convective updraft but induce more explicit (i.e. non-convective) precipitation from the microphysical scheme. The CCT controls the overall convection strength, and longer consumption time corresponds to a slower release rate of CAPE and weaker convection. The impact of higher downdraft starting height is similar to larger downdraft flux, and the parameter of TKE is much less important. The relationship between the model variables (including precipitation) and input parameters over the EASM region are found to be similar to that over the SGP region in Yang et al. (2012). The model sensitivities to the parameters, especially to those with significant importance, are also close during the selected years over the EASM region (figures not shown), confirming the transferability of parameter impacts on the mean climate across years with different EASM intensities.

Figure 6 depicts the responses of vertical profiles (averaged over $23^{\circ}-38^{\circ} \mathrm{N}, 107^{\circ}-122^{\circ} \mathrm{E}$ ) of the potential temperature, humidity, moist static energy (MSE) and cloud content to the parameters of downdraft $\left(P_{d}\right)$, entrainment $\left(P_{e}\right)$ and CCT $\left(P_{c}\right)$, i.e. the three most 
important parameters, respectively. Only the results in 2007 are shown as an example. It is found that, with stronger downdraft flux (left panels of Fig. 6), the lowlevel $(1,000-700 \mathrm{hPa})$ and high-level $(300-200 \mathrm{hPa})$ troposphere are much cooler, while the middle-level is less affected (Fig. 6a). The low-level cooling is mainly because of the intensified rain evaporation with the larger downdraft, which also moistens the low level atmosphere (Fig. 6d). Due to the cooler and wetter environment, more low-level cloud can be sustained. Contrastingly, larger entrainment can induce opposite temperature responses at low- and high-levels (Fig. 6b). Sufficient exchanging between the updraft and surrounding atmosphere increases the environmental humidity at the middle-level troposphere. However, the updrafts are prevented from penetrating further upward, resulting in a dryer and cooler uplayer atmosphere (Fig. 6b, e). The warmer low-level air is partially due to the weaker downdraft evaporation from suppressed convection, and partially due to the less cooling of convective precipitation at surface. Larger entrainment can also induce less low-level clouds and more mid-level clouds, which are more evident during daytime and nighttime, respectively (figure not shown), exaggerating the low-level warm condition. The increase of CCT tends to weaken the overall convection strength and cause wet (dry) anomaly at lower (upper) level. The MSE is also influenced due to the change of temperature and humidity conditions. The increase of entrainment induces higher MSE at low- and middle-level, while larger CCT causes larger MSE at low-level but smaller MSE at upper-level.

The responses of cloud properties can significantly affect the diurnal features of the atmospheric thermal conditions. The rainfall diurnal features may also be regulated by the perturbed parameters as the different responses of convective and explicit precipitation (Yang et al. 2012). Figure 7 presents the parameter impacts on the diurnal features of the $2 \mathrm{~m}$ air temperature and precipitation in 2007. Obviously the temperature is very sensitive to the downdraft and entrainment parameters, with the largest responses at around 09UTC (i.e. 17LST). The CCT has relatively less impact on the near surface temperature, which is consistent with that shown in Fig. 6c. The parameter impacts on the convective and explicit precipitation are different for both magnitude and diurnal phase. Larger downdraft can induce less convective precipitation during both daytime and nighttime, especially during daytime, while has weak effect on the explicit precipitation. The increase of entrainment or CCT suppresses the daytime convection but increase the explicit precipitation during nighttime. However, the impact on explicit precipitation peaks at around 12UTC for the CCT, which is several hours earlier than that for the entrainment parameter. In the model, convective and explicit precipitation usually exhibit different diurnal features. The downdraft has a weak impact on explicit precipitation and is less important for the diurnal cycle of total precipitation. Such weak impact on explicit precipitation is probably because larger downdraft can potentially induce more low-layer moisture (Fig. 6) but meanwhile cause cooler atmosphere and weaker vertical motion or low-layer convergence (figures not shown). Contrastingly, the entrainment and CCT play more important roles in the diurnal cycles of total precipitation due to their large impacts on both convective and explicit precipitation.

Yang et al. (2012) indicated that the optimized parameters could improve the simulation of precipitation frequencies of different rain rates over the SGP region, especially for heavy rainfall events. Here similar results can be found over the EASM region (figure not shown). However, the dependence of rain-rate spectrum on different parameters could be different. In Fig. 8 we present the responses of rain-rate spectrums to the parameters of downdraft $\left(P_{d}\right)$, entrainment $\left(P_{e}\right)$, and CCT $\left(P_{c}\right)$ in 2007, respectively. The rain-rate spectrums are defined in two ways: (1) the frequency distributions of different rain rates, and (2) the rain rates at different percentiles. From the frequency distribution plots (top panels of Fig. 8), it is seen that the increase of downdraft strength or CCT results in higher (lower) frequency of light (heavy) rainfall events. Contrastingly, the enhanced entrainment decreases the frequency of light rainfall events but increase the heavy ones, although the mean convective precipitation are reduced (Fig. 7). Similar results can be found in the plot of rain rates at different percentiles (bottom panels of Fig. 8), that the rain rates at percentiles above 70th are significantly reduced with larger downdraft flux or CCT. While with larger entrainment flux, the rain rates above (below) 90th percentile are increased (decreased), indicating that large entrainment suppresses and delays the convection development but at the same time build up more atmospheric instability and water vapor (Fig. 6), favoring the occurrence of heavy rainfall events.

Above results mainly show the parameter impacts on the domain average properties of the model system. However, the EASM precipitation is characterized by complex regional variability (Ding and Chan 2005). To study the regional features of parameter impacts, Fig. 9 presents the spatial distributions of correlations of convective precipitation with the parameters of downdraft $\left(P_{d}\right)$, entrainment $\left(P_{e}\right)$ and CCT $\left(P_{c}\right)$, respectively. As mentioned above, the increases of the three parameters all tend to decrease the convective precipitation over most regions but with increased rainfall over small areas probably caused by the circulation response to convection. The response patterns of convection to the three parameters are different as shown in the 4th column of Fig. 9, which depicts the most 
(a) $2 \mathrm{~m}$ air temperature

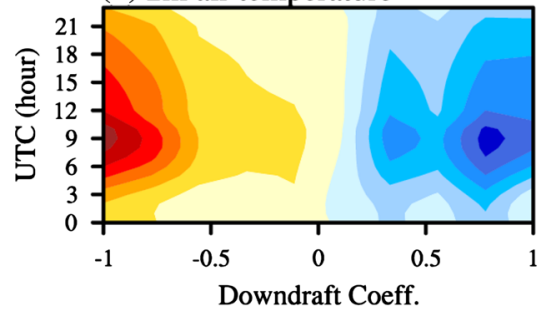

(d) Convective precipitation

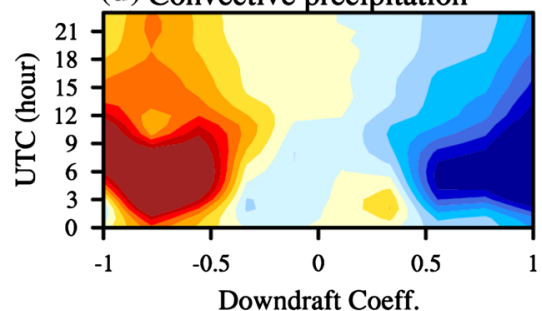

(g) Explicit precipitation

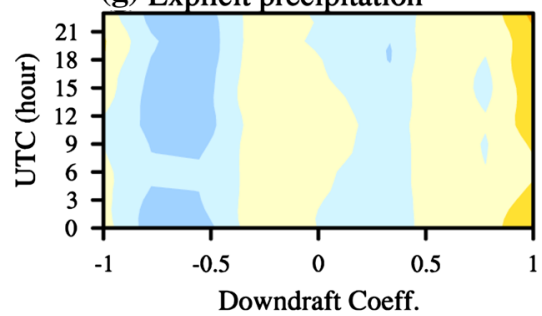

(j) Total precipitation

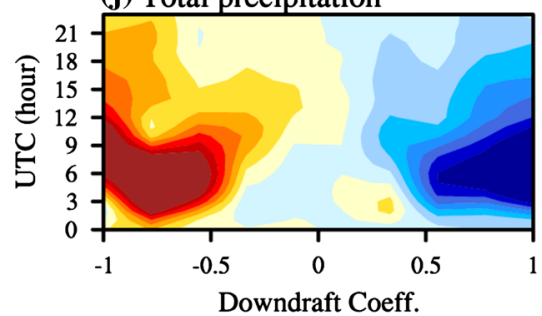

(b) $2 \mathrm{~m}$ air temperature

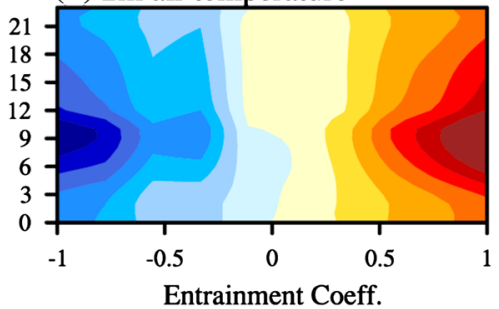

(e) Convective precipitation

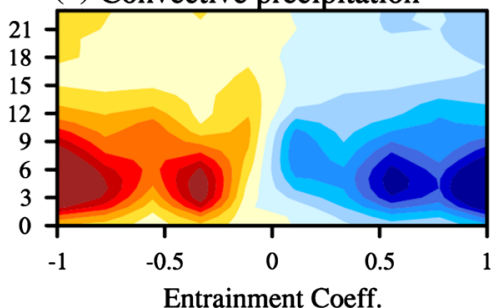

(h) Explicit precipitation

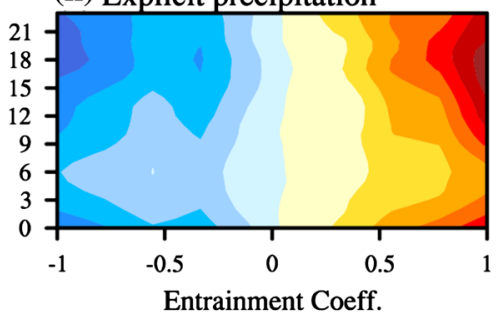

(k) Total precipitation

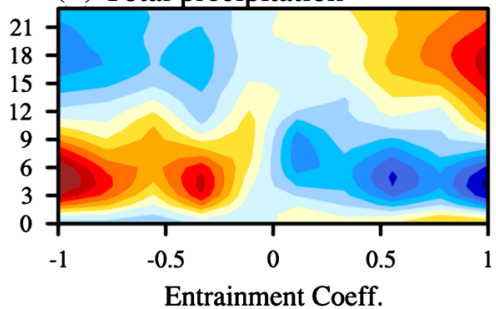

(c) $2 \mathrm{~m}$ air temperature

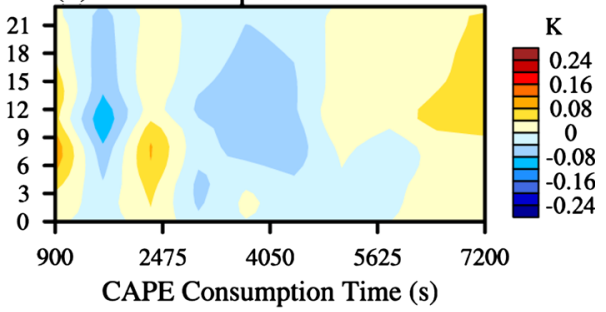

(f) Convective precipitation

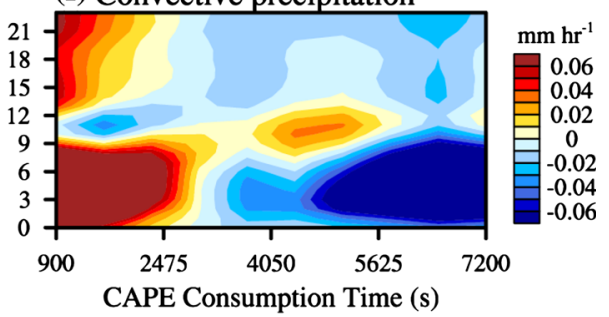

(i) Explicit precipitation

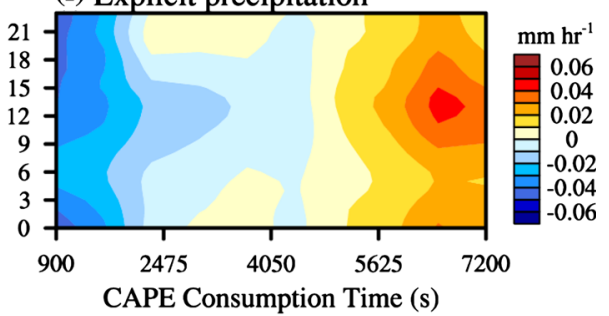

(l) Total precipitation

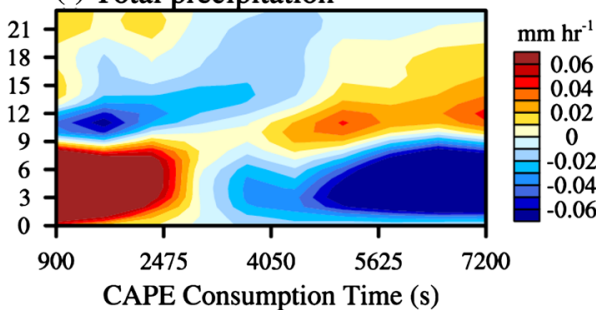

Fig. 7 Responses of diurnal cycles (averaged over $23^{\circ}-38^{\circ} \mathrm{N}, 107^{\circ}-$ $122^{\circ} \mathrm{E}$ ) for $\mathbf{a}-\mathbf{c} 2 \mathrm{~m}$ air temperature, $\mathbf{d}-\mathbf{f}$ convective precipitation, $\mathbf{g}-\mathbf{i}$ explicit precipitation and $\mathbf{j}-\mathbf{I}$ total precipitation to (X-axis) the parameters of (left) downdraft $\left(P_{d}\right)$, (middle) entrainment $\left(P_{e}\right)$ and

important parameter at each grid point. Compared with the precipitation pattern in Fig. 4, it is found that the CCT is the most important over areas with large rainfall amount in each year. The downdraft parameter is more important for most areas over the northern (especially northwestern) regions, with small year-to-year differences due to the precipitation change there (Fig. 4). Such large impacts of the downdraft parameter are probably because the dry lowlevel air there favors rain-water evaporation in the downdraft. Convective precipitation over terrain regions (Fig. 2) is also sensitive to the downdraft parameter. The entrainment parameter is the most important for most southern regions surrounding the main rain-band, but has less impact (right) CAPE consumption time $\left(P_{c}\right)$ in 2007, respectively. All values are given as anomalies at each tenth bin within the parameter space, i.e. subtracted by the average of the 10 bins

over the northern part probably due to the little dilution effect of entrainment on the dry updraft. The entrainment parameter is also important over Sichuan area (around $30^{\circ} \mathrm{N}, 107^{\circ} \mathrm{E}$ ) and a west-eastward elongated band (the northern portion of the Mei-yu band, except in 2005) where the nocturnal precipitation is larger (figure not shown). This is probably because the nighttime atmospheric upward motion is much weaker than that during daytime, favoring smaller cloud radius and stronger entrainments in the model (Kain 2004).

Figure 10 also presents the correlation maps of the total precipitation with different parameters. It can be noted a similar response of the total precipitation with that of 
(a)

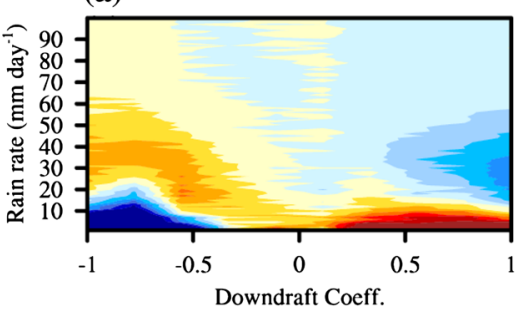

(d)

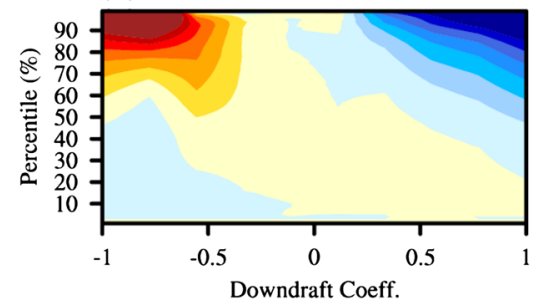

(b)

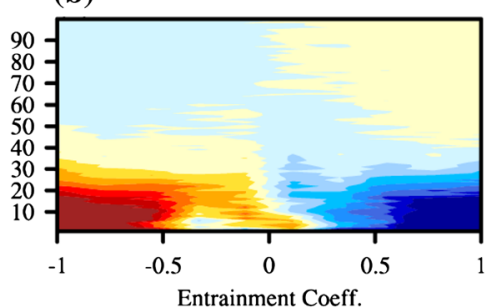

(e)

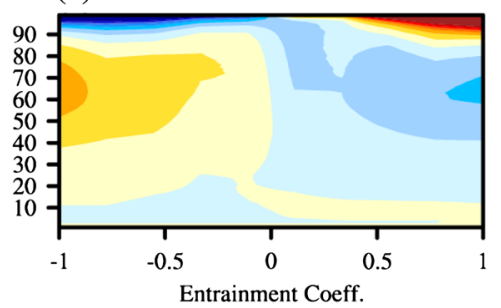

(c)

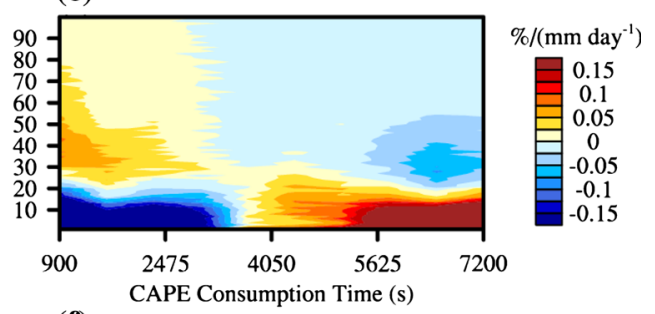

(f)

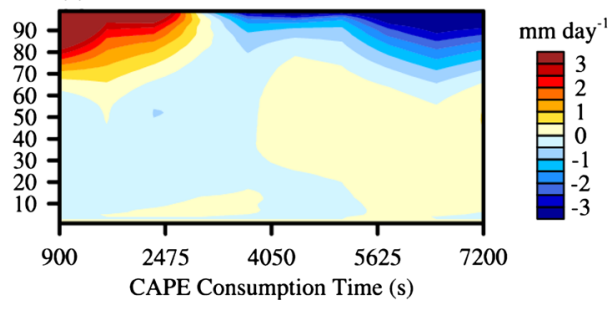

Fig. 8 Responses of rain-rate spectrums to (X-axis) the parameters of a, $\mathbf{d}$ downdraft $\left(P_{d}\right), \mathbf{b}-\mathbf{e}$ entrainment $\left(P_{e}\right)$ and $\mathbf{c}-\mathbf{f}$ CAPE consumption time $\left(P_{c}\right)$ in 2007. Rain-rate spectrums are represented by (top) frequency distributions of different rain rates and (bottom) rain rates at different percentiles, respectively. All values are given as anomalies at each tenth bin within the parameter space, i.e. subtracted by the average of the 10 bins
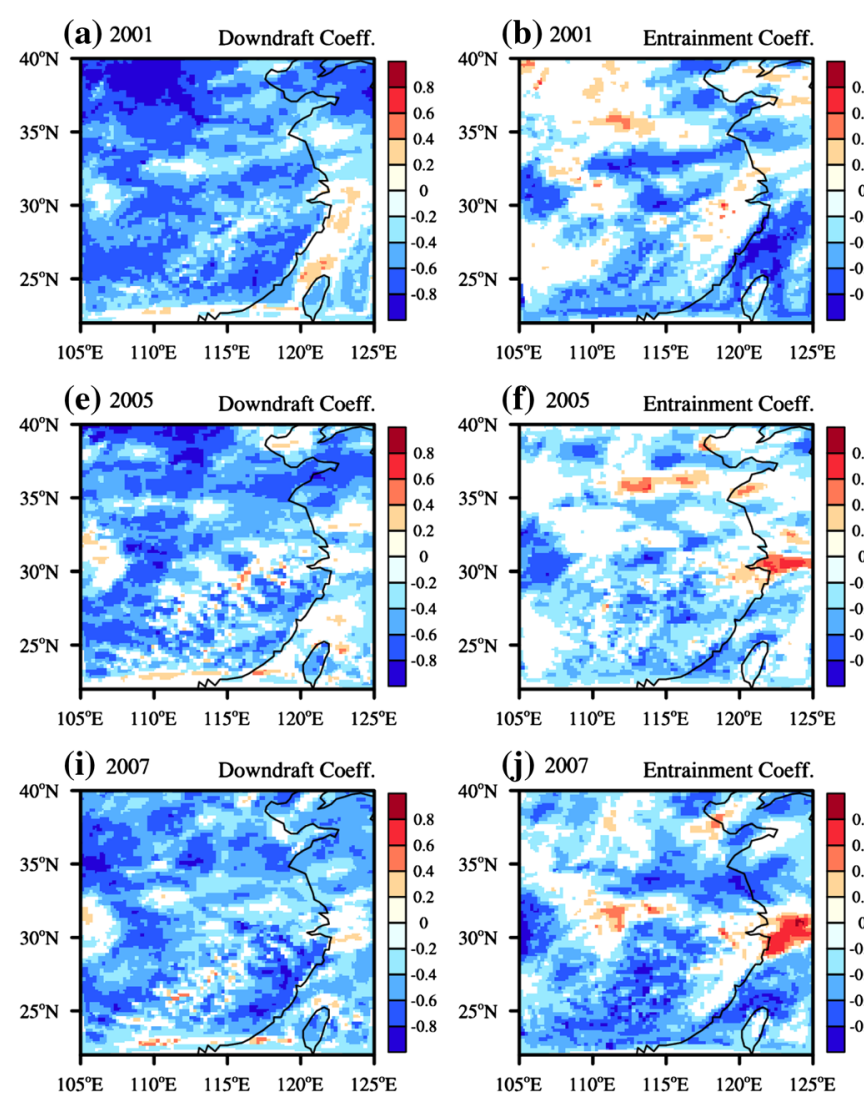

Fig. 9 Spatial distributions of correlations of convective precipitation with parameters of (1st column) downdraft $\left(P_{d}\right)$, (2nd column) entrainment $\left(P_{e}\right)$ and $(3 r d$ column $)$ CAPE consumption time $\left(P_{c}\right)$ based on the 150 experiments in (top) 2001, (middle) 2005 and (bottom) 2007, respectively. The 4th column indicates the most (c) 2001
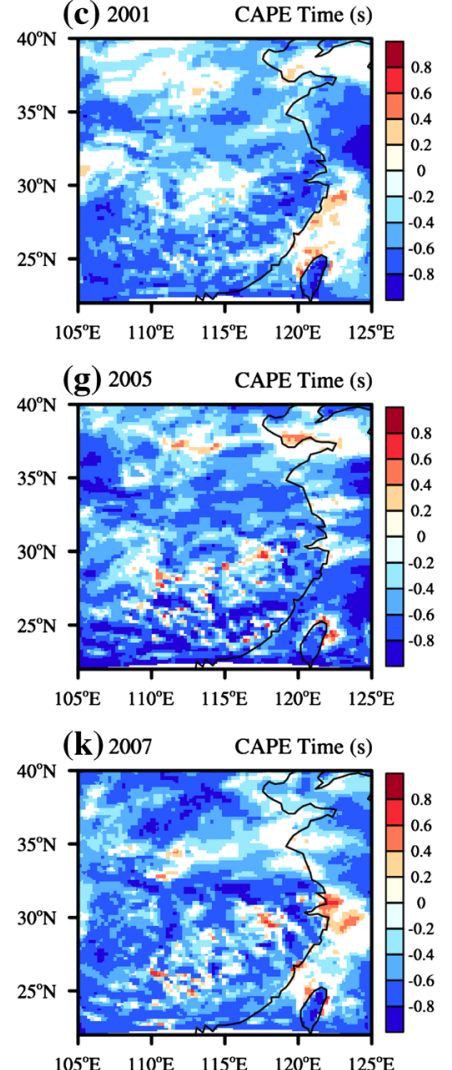

(d) $2001 \quad$ Relative importance

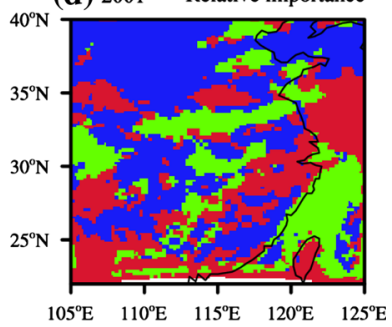

(h) 2005 Relative importance

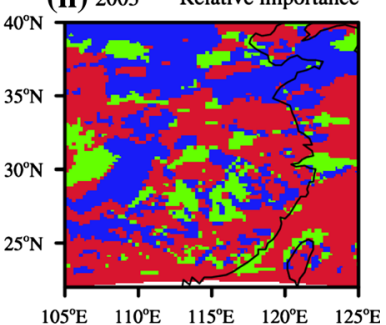

(l) $2007 \quad$ Relative importance

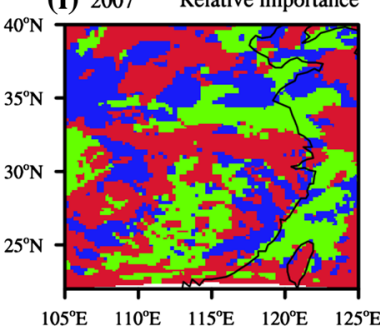

important parameter at each grid point by different colors, i.e. blue for $P_{d}$, green for $P_{e}$ and red for $P_{c}$. The importance ranking is derived based on the regression coefficients between the convective precipitation and parameters. Only points statistically significant at the $99 \%$ confidence level are shown 

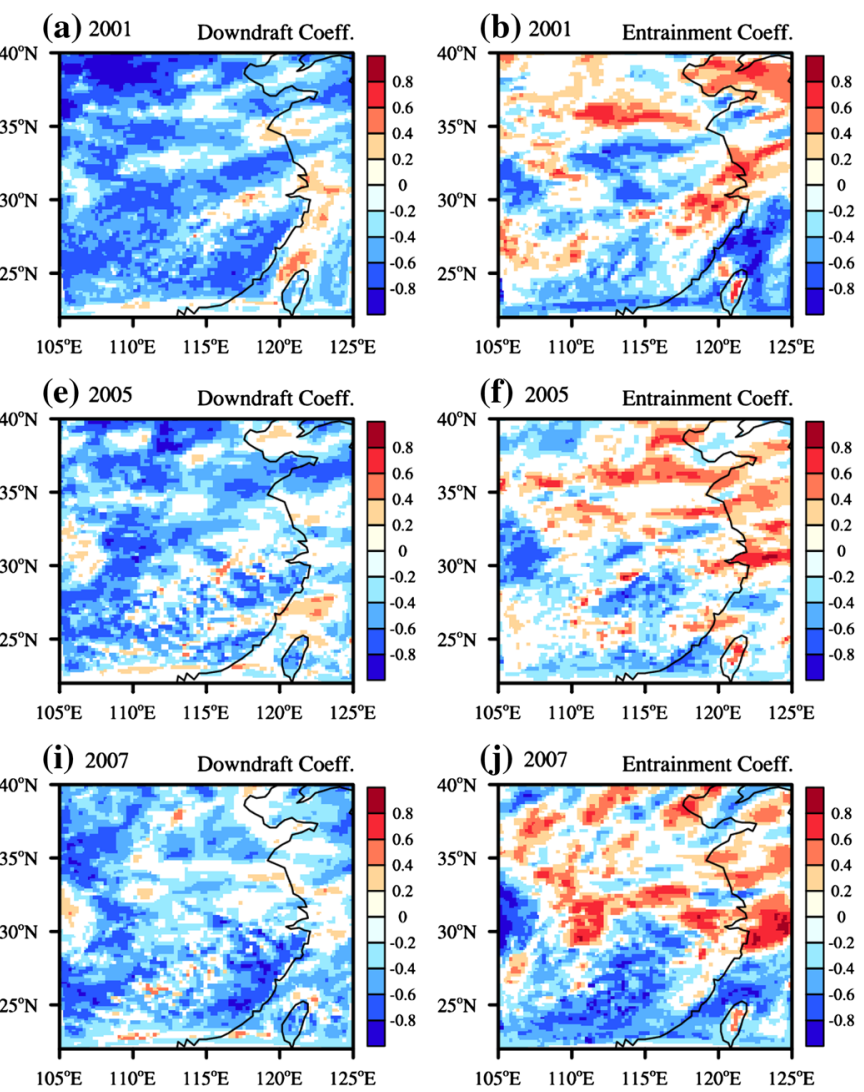
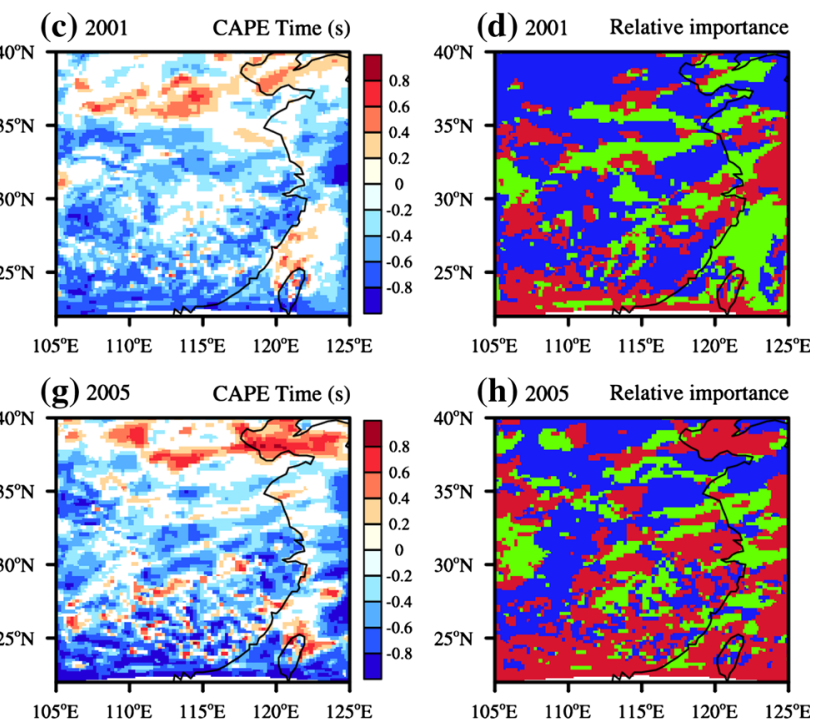

(h) 2005 Relative importance

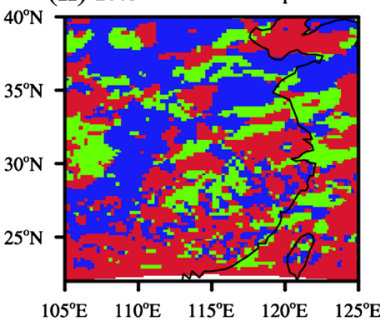

(k) 2007

CAPE Time (s)
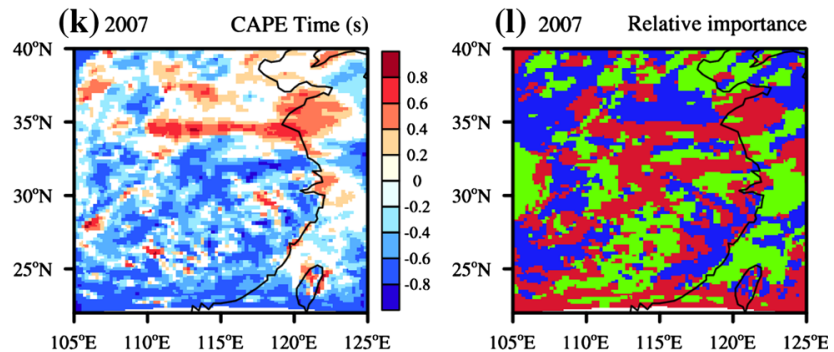

Fig. 10 Same as Fig. 9 but for the total precipitation

convective precipitation to the downdraft parameter. Contrastingly, different features of total and convective precipitation are found for the other two parameters, indicating strong influences of these two parameters on the explicit precipitation (Fig. 7). Here it is shown that, with larger entrainment the rainfall distribution may be shifted northward probably resulting from the modulation of entrainment on the precipitation process (Fig. 8). This may be related to the northward shift of rain-belt simulation in some model studies (e.g. Lee and Suh 2000). The relative importance of each parameter for total precipitation (4th column in Fig. 10) is similar to that for convective precipitation (4th column in Fig. 9), except over the northern part of the Mei-yu band in 2007 where the CCT (entrainment) is more important for total (convective) precipitation, implying the compensated responses of convective and explicit precipitation to the entrainment parameter there.

\subsection{Impacts of optimization on monsoon circulation and precipitation}

Large scale circulations are important for the generation of precipitation, while the condensational heat release from precipitation affect the circulation in turn (Emanuel et al.
1994; Lu et al. 2009; Sampe and Xie 2010). As the reinitiation mode is employed in our optimization experiments, the response of large scale circulation could not be reflected entirely. Therefore, we firstly conduct several free-run simulations with the standard and optimized parameters for the cases in this study and the SGP case of Yang et al. (2012). The SGP results (figure not shown) indicate that the precipitation distribution simulated by the standard WRF evidently drifts away from observation but is remarkably improved by applying the optimized parameters. In contrast, the sensitivity of precipitation pattern to the parameters is less prominent over the EASM region, probably because the large-scale forcing is stronger over the EASM region than over the SGP where the precipitation bias could induce larger feedback.

However, the above experiments are performed over a relatively small domain (smaller dashed box in Fig. 2) during a short-term period (i.e. 1 month). To further study the impacts of the optimized parameters on the monsoon circulation and subsequently the EASM precipitation, two sets of 10-summer simulations (May-Aug, 2000-2009) at a relatively larger domain (larger dashed box in Fig. 2) are conducted with the standard and optimized parameters derived from the optimization experiments. It is noted that among the three selected years with respectively weak, 

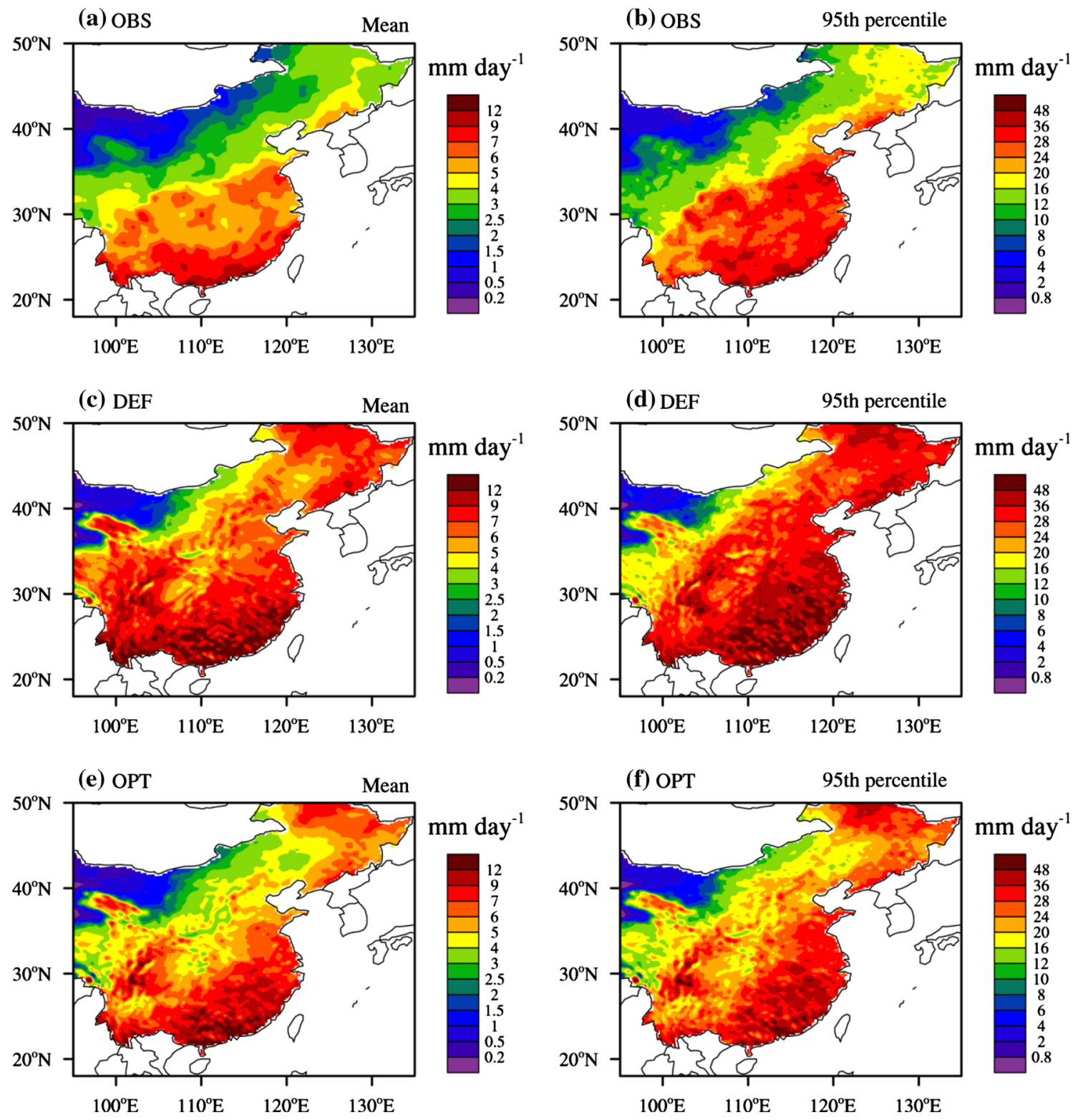

Fig. 11 Spatial distributions of the (left) mean precipitation and (right) 95th percentile daily precipitation during summer (JJA) from 2000 to 2009 , based on the $\mathbf{a}, \mathbf{b}$ observation, $\mathbf{c}, \mathbf{d}$ DEF and e, f OPT simulations, respectively

normal and strong EASMs, the differences of the optimal parameter values are small (Table 2), especially for those with significant impacts on model performance (e.g. $P_{d}$ and $\left.P_{c}\right)$. Besides that, the responses of the simulated climate system to parameters are also similar across different years. It is expected that the three optimal parameter sets will give similar results when being applied in long-term simulations. Therefore, in this study we only use the optimal parameter set derived in 2007 for the 10-summer simulations. Hereafter, the two 10 -summer simulations with the default and optimized parameters are referred to as DEF and OPT simulations, respectively.

\subsubsection{Summer mean features}

Figure 11 shows the spatial distributions of the mean precipitation and 95 th percentile daily precipitation during summer (JJA) from 2000 to 2009, based on the observation, DEF and OPT simulations, respectively. In observation (Fig. 11a), the main rainfall center is located at the southern coastal area with the maximum intensity exceeding $9 \mathrm{~mm}$ day $^{-1}$, while a separate rain-belt is also detected around the middle and lower reaches of YRB. As the shortterm experiments (Fig. 4), the summer mean precipitation is evidently overestimated by the standard WRF but 
(a) OBS

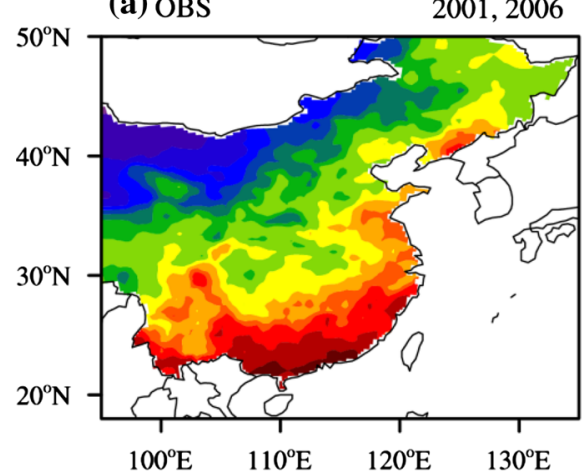

(c) DEF

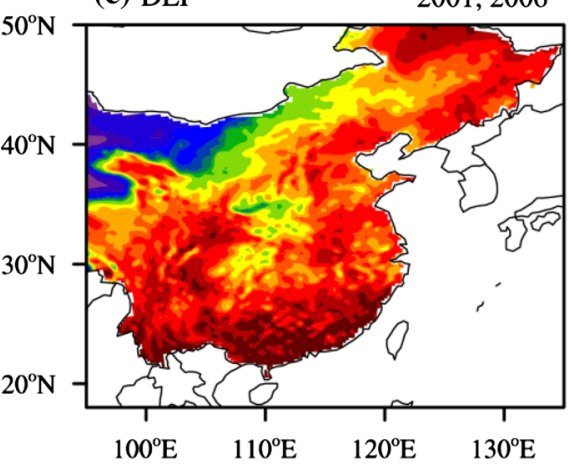

(e) OPT

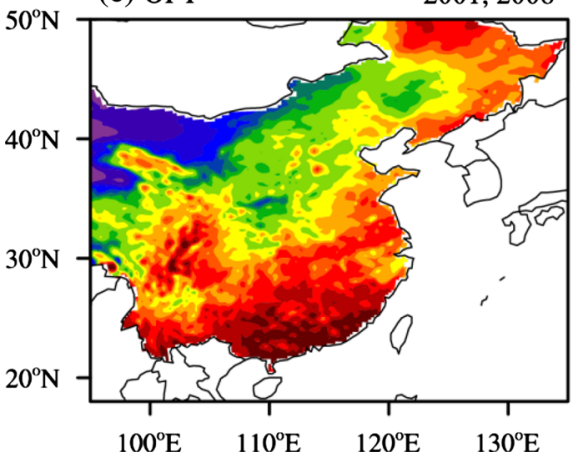

(b) OBS
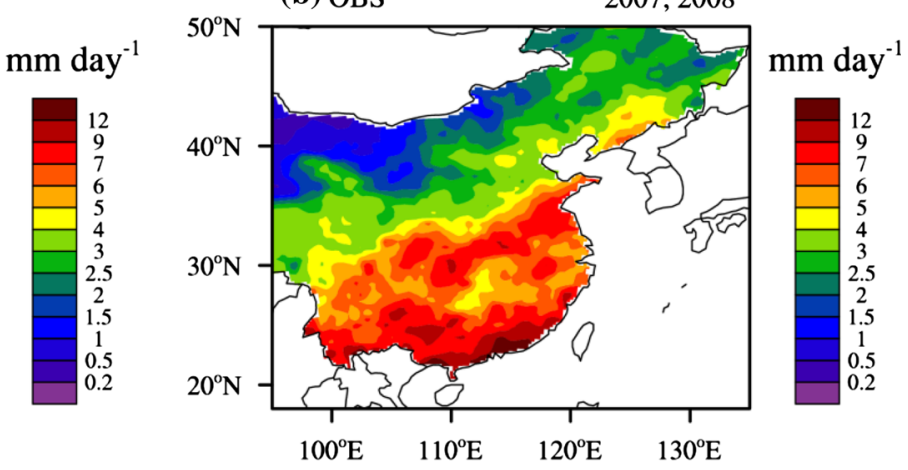

(d) DEF
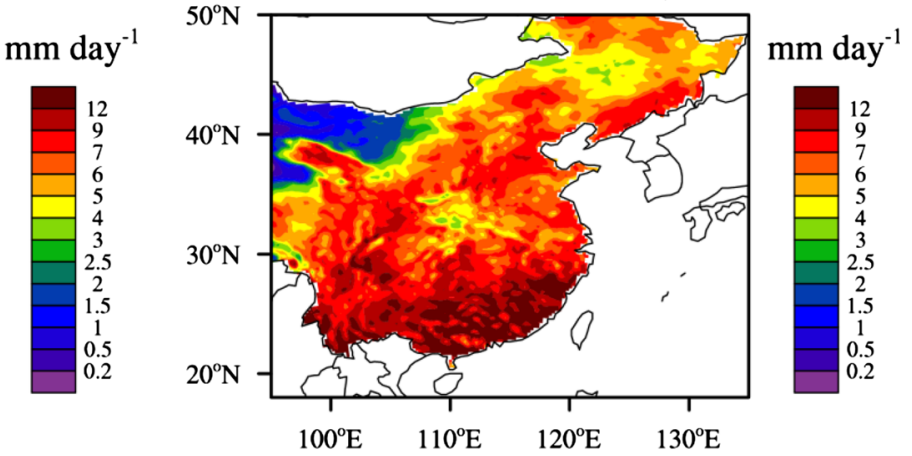

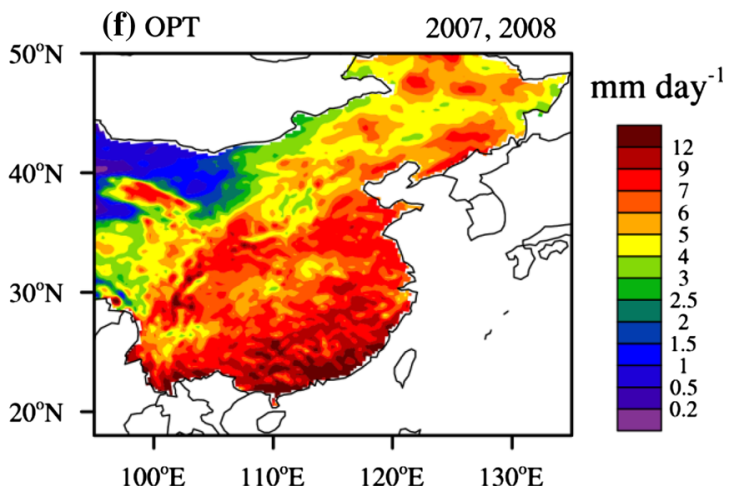

Fig. 12 Spatial distributions of the summer mean precipitation during (left) weak EASM years (2001 and 2006) and (right) strong EASM years (2007 and 2008), based on the a, b cobservation, $\mathbf{c}, \mathbf{d}$ DEF and e, f OPT simulations, respectively

remarkably reduced by using the optimized parameters. However, both the DEF and OPT simulations fail to capture the maximum rainfall center over the YRB region. Figure $11 \mathrm{~b}$ shows that the observed rain rates at 95 th percentile are about $28 \mathrm{~mm} \mathrm{day}^{-1}$ in most areas of southern China and the YRB region. We can also find the DEF simulation overestimates the rain rates over the entire domain, with the maximum value above $36 \mathrm{~mm}$ day $^{-1}$ in southern China. By applying the optimized parameters, the results show better agreement with observation.

The spatial distributions of summer mean precipitation during weak EASM years (2001 and 2006, based on the YRB Mei-yu in Fig. 1) and strong EASM years (2007 and 2008) are shown in Fig. 12, respectively. During weak EASM years, the standard WRF evidently overestimates the precipitation magnitude especially over northern and northeastern China. Both the precipitation magnitude and pattern are better simulated in the OPT simulation. During strong EASM years, the standard WRF overestimates the precipitation over southern and northern China but fails to produce the Mei-yu band at the YRB region. Contrastingly, the OPT simulation successfully reproduces the Mei-yu band. The OPT model can also better simulate the precipitation anomalies over the YRB region and southern China as in observation, i.e. positive (negative) anomaly over the YRB region (southern China) during strong EASM years with respect to during weak EASM years.

The water vapors for the EASM precipitation are mainly transported by the low-level southwesterly along the 

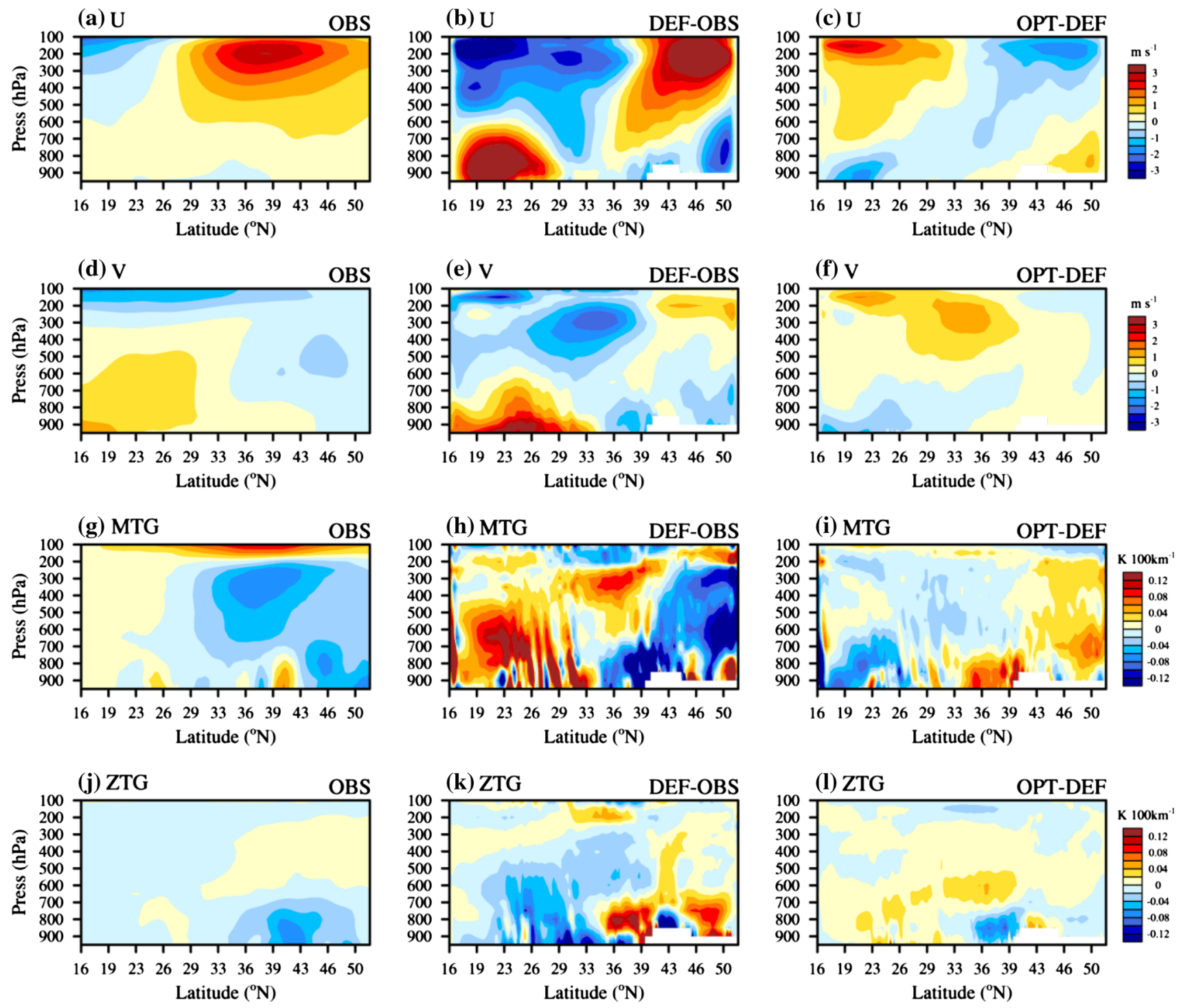

Fig. 13 Height-latitude cross sections (along $\sim 115^{\circ} \mathrm{E}$, in JJA from 2000 to 2009) of a-c U-wind, d-f V-wind, $\mathbf{g}-\mathbf{i}$ meridional temperature gradient $(M T G)$, and $\mathbf{j}-\mathbf{l}$ zonal temperature gradient $(Z T G)$ for

western Pacific subtropical high (Zhou and Yu 2005). Figure 13 (top two rows) describes the height-latitude vertical distributions (along $\sim 115^{\circ} \mathrm{E}$ ) of the observed $\mathrm{U}$-wind and $\mathrm{V}$-wind (note that the winds are calculated based on the model projection), respectively. The difference between the DEF simulation and observation (hereafter DEF-OBS difference), as well as the difference between the OPT and DEF simulations (hereafter OPTDEF difference), are also shown. The observed U-wind plot shows strong upper-layer westerly (easterly) winds to the north (south) of $26^{\circ} \mathrm{N}$, while the V-wind plot shows strong southerly (northerly) winds at lower- (upper-) levels to the south of $35^{\circ} \mathrm{N}$. The whole layers to the north of $35^{\circ} \mathrm{N}$ are dominated by northerlies. Compared with observation, the standard WRF produces apparent westerly (easterly) the (left) observation, (middle) DEF-OBS difference and (right) OPT-DEF difference, respectively

biases to the south (north) of $33^{\circ} \mathrm{N}$ at low-level, and an opposite bias pattern at upper-level, implying a low(upper-) level cyclone (anticyclone) circulation bias (figure not shown). When using the optimized parameters, the biases are reduced to some extent indicated by the reversed pattern of the OPT-DEF difference from that of the DEFOBS difference. Similar improvement can also be found for the $\mathrm{V}$-wind component.

Since only the convective parameters are perturbed, the circulation change is expected to be a response to the redistribution of the precipitation condensational heating. The upper-level zonal winds are mainly controlled by the troposphere meridional temperature gradient (MTG) through the thermal wind balance (Lin and Lu 2008; Zhang and Huang 2011; Xiao and Zhang 2012). In Fig. 13 


\section{(a) OBS}

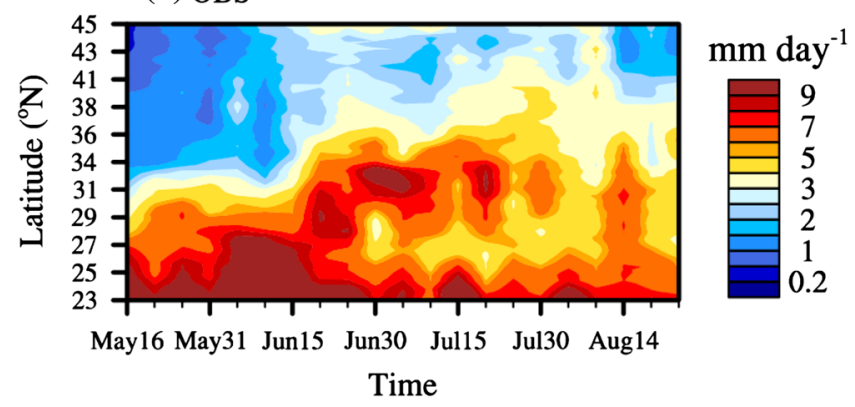

(b) DEF

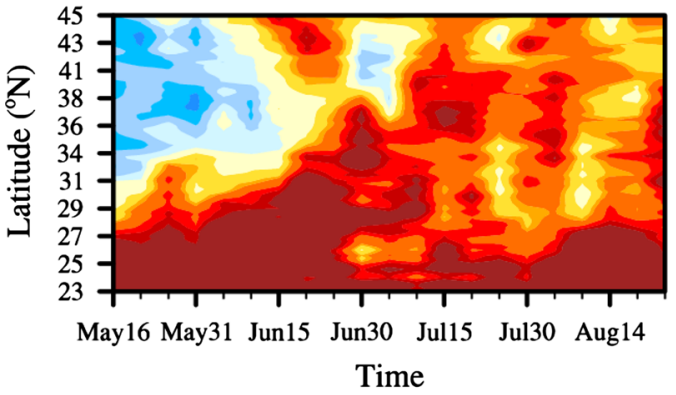

(d) OPT

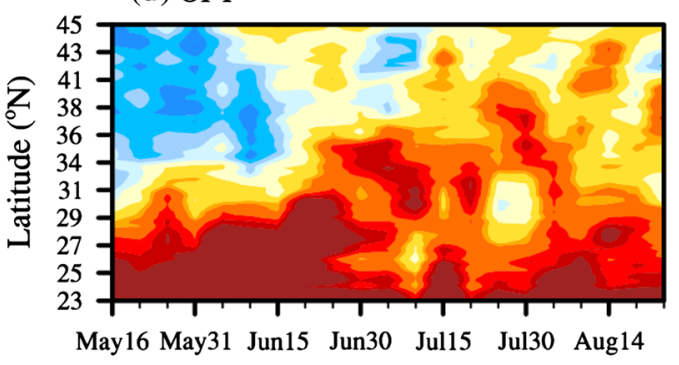

Time (c) DEF-OBS
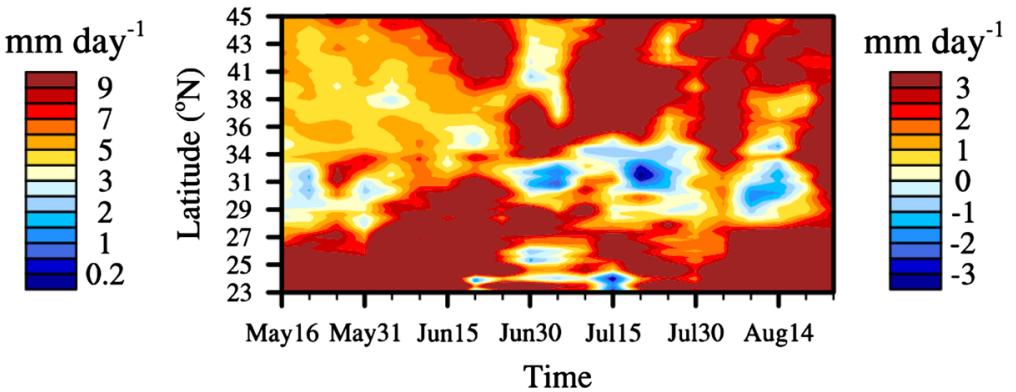

(e) OPT-DEF
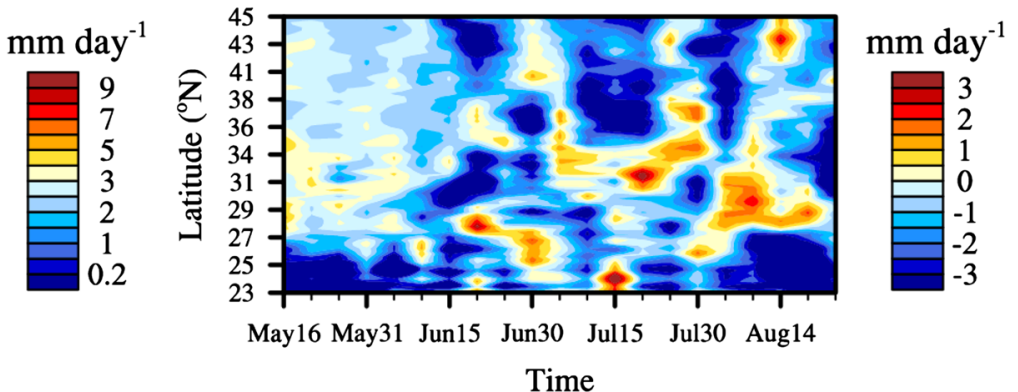

Fig. 14 Latitude-time sections of climatological (2000-2009) pentad precipitation over eastern China $\left(110^{\circ} \mathrm{E}-120^{\circ} \mathrm{E}\right)$ from $16 \mathrm{May}$ to 30 Aug in the a observation, $\mathbf{b}$ DEF and $\mathbf{d}$ OPT simulations. The DEF-OBS difference and OPT-DEF difference are also shown in $\mathbf{c}$ and e, respectively

(bottom 2 rows), we also presents the vertical distributions of MTG and zonal temperature gradient (ZTG), respectively. Corresponding to the U-wind biases, large positive (negative) MGT biases to the south (north) of $33^{\circ} \mathrm{N}$ are also found in the standard WRF (Fig. 13h) but reduced in the OPT simulation to some extent. The simulated ZTG is also improved by using the optimized parameters. In fact, the improved V-wind can be explained as responses to the improved precipitation heating through the Sverdrup balance (i.e. low-level southerly and upper-level northerly over heating regions, Harrison et al. 2001).

\subsubsection{Seasonal propagation and sub-seasonal variation}

The seasonal propagation of the EASM and the associated rain-belt advances are distinct features over the EASM region (Ding and Chan 2005). Figure 14 depicts the climatological (2000-2009) seasonal variation (from 16 May to $30 \mathrm{Aug}$ ) of the monsoon precipitation at time-latitude sections $\left(110^{\circ} \mathrm{E}-120^{\circ} \mathrm{E}\right)$, based on the observation, DEF and OPT simulations, respectively. The DEF-OBS and OPT-DEF differences are also shown. In observation (Fig. 14a), the main rain-belt is located over southern China to the south of $27^{\circ} \mathrm{N}$ from 16 May to 20 Jun. Then the rain-belt suddenly jumps northward to the YRB region forming the Mei-yu precipitation. The Mei-yu decreases from around $25 \mathrm{Jul}$, accompanied by the increased northern China rainfall. In Fig. 14b, the basic evolution features of precipitation are almost produced by the standard WRF. However, when compared with observation, the simulated YRB Meiyu penetrates too north on around $30 \mathrm{Jun}$, and jumps too early to northern China, i.e. the main rain-band on $15 \mathrm{Jul}$ is still located over the YRB region in observation while over northern China in the DEF simulation. Contrastingly, the OPT simulations (Fig. 14d) exhibit better agreements with observation for both the 
(a) OBS

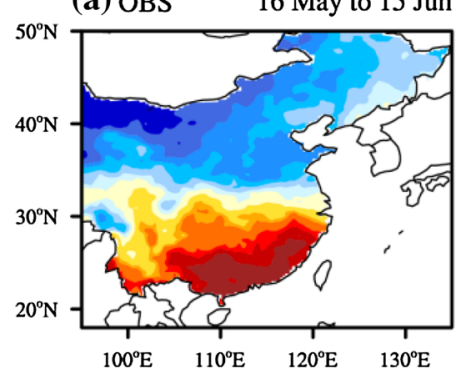

(d) OBS

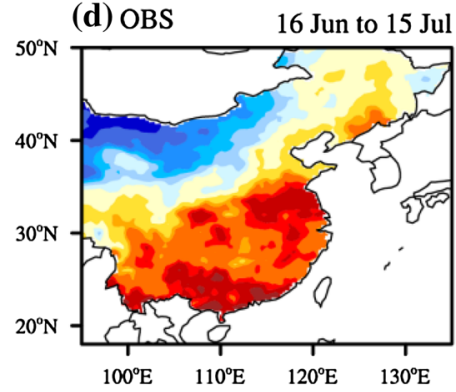

(g) OBS

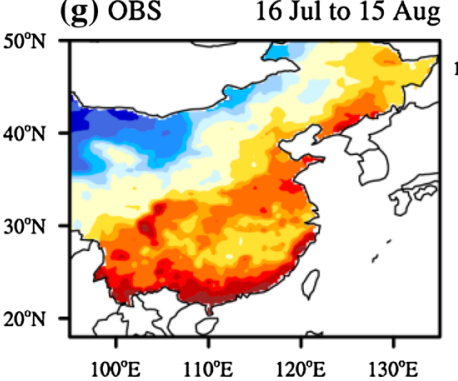

(b) DEF-OBS 16 May to 15 Jun
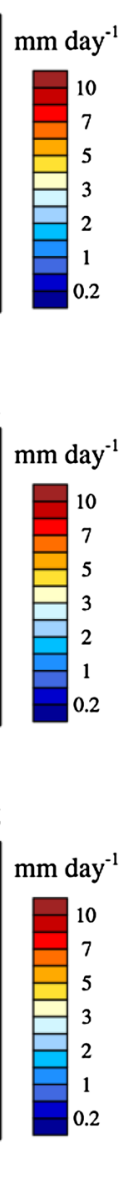

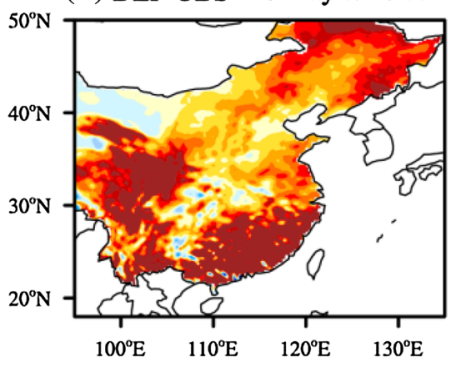

(e) DEF-OBS

(h) DEF-OBS $16 \mathrm{Jul}$ to $15 \mathrm{Aug}$
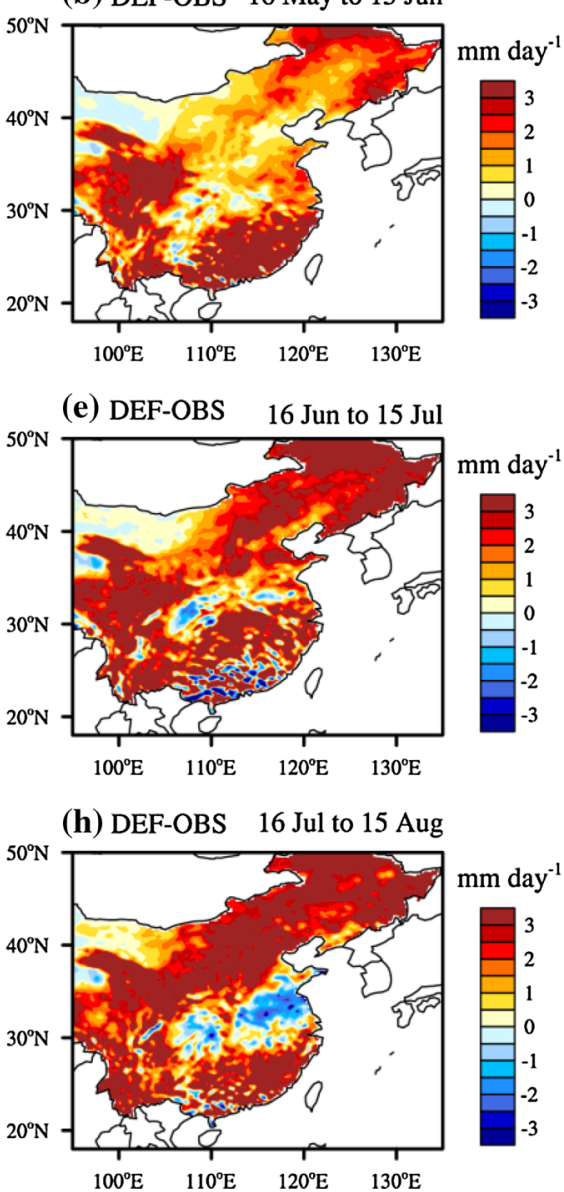

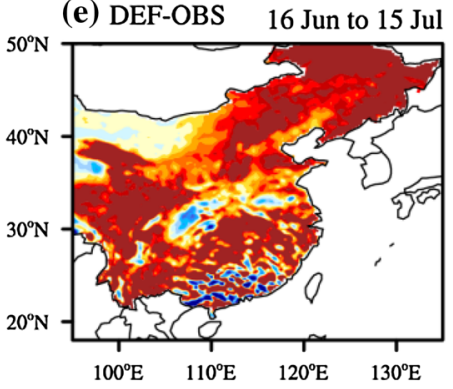

(c) OPT-DEF 16 May to 15 Jun

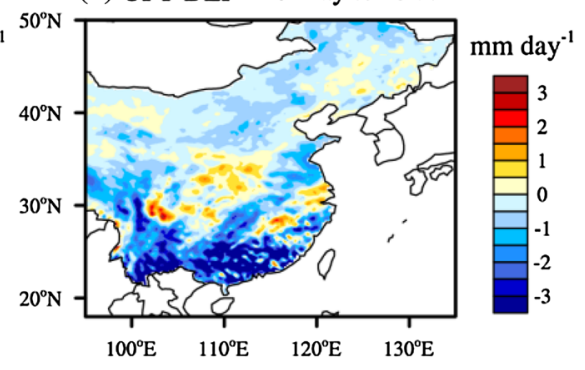

(f) OPT-DEF 16 Jun to $15 \mathrm{Jul}$

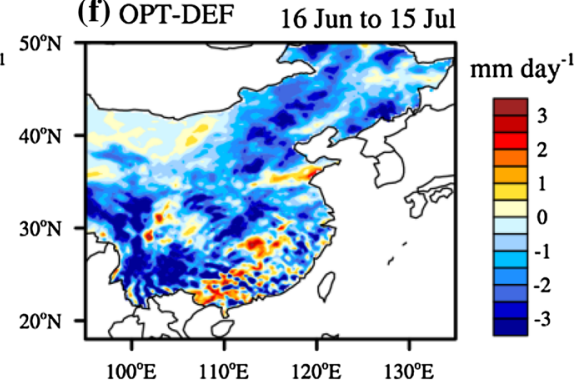

(i) OPT-DEF 16 Jul to $15 \mathrm{Aug}$

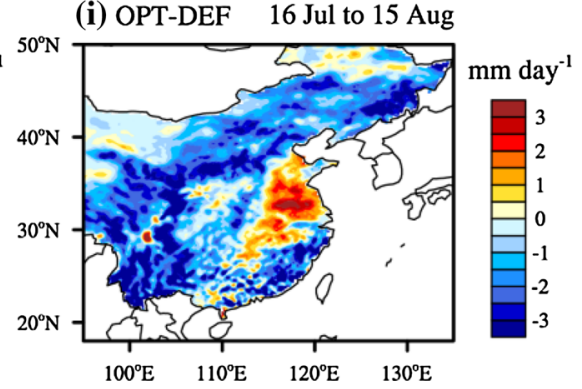

Fig. 15 Spatial distributions of mean precipitation (2000-2009) during a-c 16 May to 15 Jun, d-f 16 Jun to 15 Jul and $\mathbf{h}-\mathbf{i} 16$ Jul to 15 Aug for the (left) observation, (middle) DEF-OBS difference and (right) OPT-DEF difference, respectively

precipitation magnitude and seasonal propagation features. The DEF-OBS plot (Fig. 14c) shows large positive biases over southern China throughout the warm season and over northern China from the end of Jun, and negative biases over the YRB region from 30 Jun. Opposite distribution of the OPT-DEF difference can be found, indicating the precipitation magnitudes, seasonal variation, as well as precipitation patterns at different stages of the rainy season, are all improved by applying the optimized parameters.

To further study the regional features of the EASM precipitation at different monsoon stages, the spatial distributions of the observed precipitation during 16 May to $15 \mathrm{Jun}, 16 \mathrm{Jun}$ to $15 \mathrm{Jul}$, and $16 \mathrm{Jul}$ to $15 \mathrm{Aug}$ are presented in Fig. 15, respectively. The DEF-OBS and OPT-DEF differences are also shown. In observation, the main rainband is located in southern China from 16 May to 15 Jun, corresponding to the pre-summer precipitation in China. The precipitation advances northward to the YRB region during $16 \mathrm{Jun}$ to $15 \mathrm{Jul}$, and then further northward to northern and northeastern China. The DEF-OBS difference plots (2nd column in Fig. 15) show that the standard WRF overestimates the precipitation over most areas but with negative biases over some regions during the three periods. During the first stage, the biases are mainly positive in the standard WRF except for weak negative biases over areas around $\left(30^{\circ} \mathrm{N}, 108^{\circ} \mathrm{E}\right.$, Fig. $\left.15 \mathrm{~b}\right)$. Contrastingly, there exists a positive OPT-DEF difference around $\left(30^{\circ} \mathrm{N}, 108^{\circ} \mathrm{E}\right)$ with other areas showing negative differences, implying a positive impact of the optimized parameters on the simulated precipitation distribution. During the second stagy, negative differences are found in the southern coastal area and along a west-east band at around $30^{\circ} \mathrm{N}$ in the DEFOBS plot. A reversed pattern is almost seen in the OPTDEF plot except for a little northward shift of location. During the last rainy stage, the precipitation in the standard WRF is clearly underestimated (overestimated) over the YRB region (surrounding regions). While the optimized parameters are applied, such bias can be remarkably reduced. The circulation features at different rainy stages are also improved correspondingly by using the optimized parameters (figure not shown). 
Table 3 Correlation coefficients of observed climatological pentad precipitation (2000-2009, from 16 May to 30 Aug) with that simulated by the standard and optimized WRF over the 5 sub-regions depicted in Fig. 2

\begin{tabular}{llllll}
\hline & SC & YRB & NC & NEC & NWC \\
\hline Default & 0.86 & 0.80 & 0.85 & 0.83 & 0.77 \\
Optimized & 0.94 & 0.78 & 0.94 & 0.86 & 0.77 \\
\hline
\end{tabular}

The correlations between the observed and simulated seasonal variations of the monsoon precipitation over five sub-regions (depicted in Fig. 2) are summarized in Table 3, suggesting that by using the optimized parameters the correlation coefficients are increased over most regions, especially over southern China (0.94 vs. 0.86 in DEF) and northern China (0.94 vs. 0.85).

The climatological intra-seasonal oscillation is an essential component of the EASM system, which strongly regulates the onset and retreat of the EASM rainfall (Krishnamurti 1985; Wang and Xu 1997; Kang et al. 1999; Mao et al. 2010). Figure 16 presents the first two leading EOF modes (EOF1 and EOF2) of the climatological (2000-2009) pentad precipitation from 16 May to 30 Aug based on the observation, DEF and OPT simulations. In

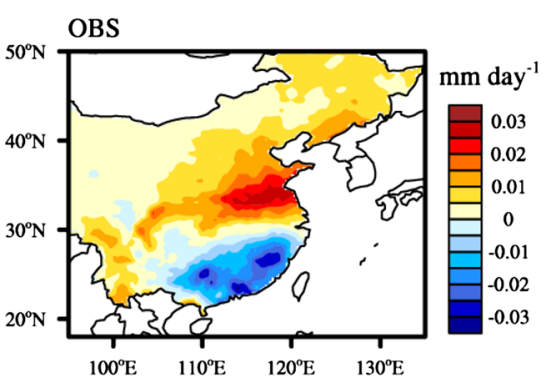

(a) EOF1
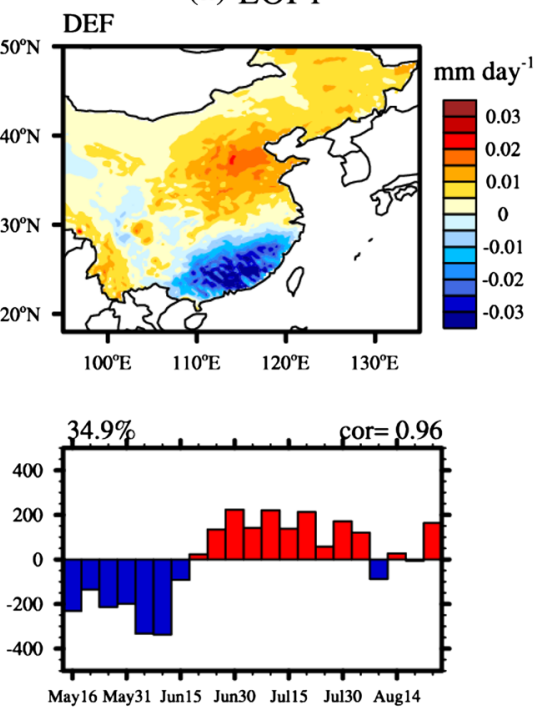

Time

(b) EOF2
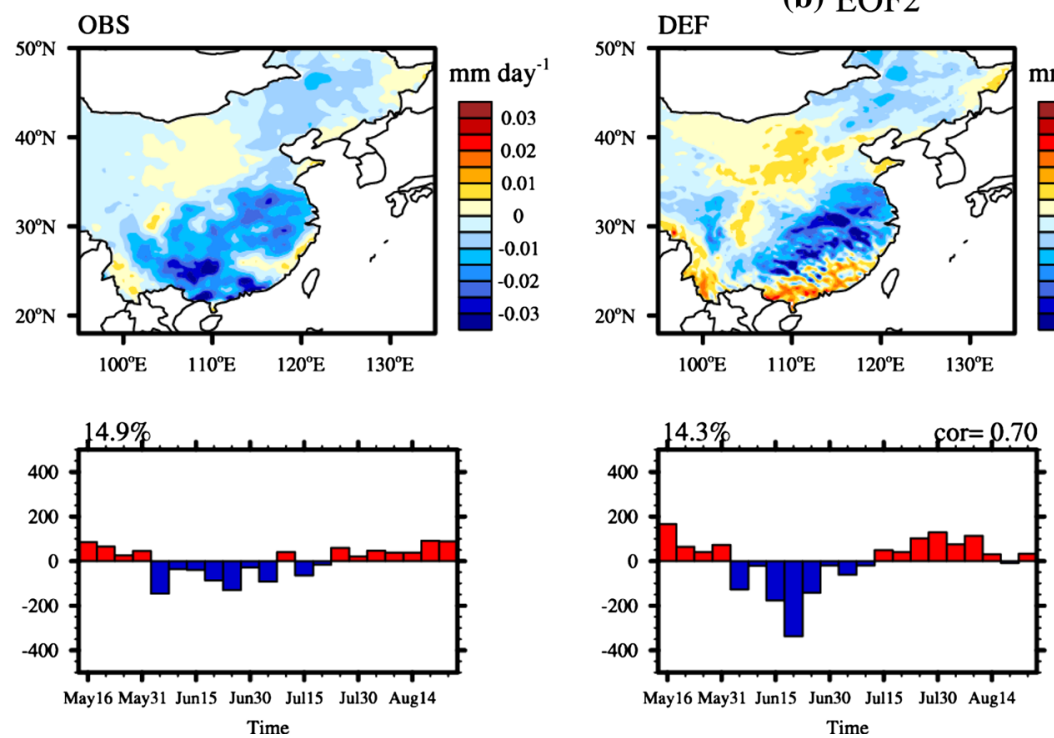
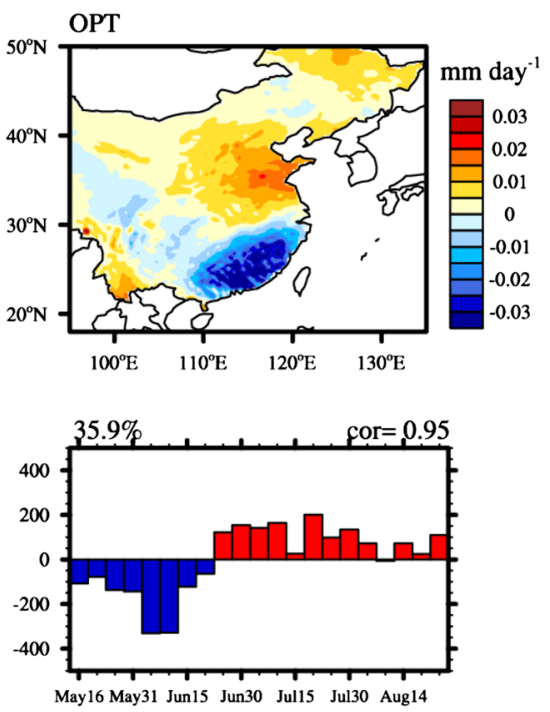

Time
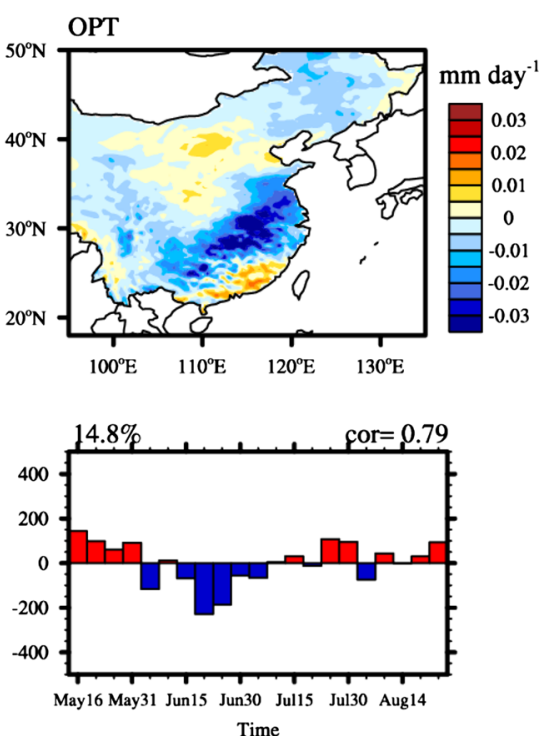

Fig. 16 The a first and $\mathbf{b}$ second EOF modes of the climatological pentad precipitation (2000-2009, from 16 May to 30 Aug), along with their principal components $(P C s)$, based on the (left) observation, (middle) DEF and (right) OPT simulations, respectively. The contributions $(\%)$ of each mode to the total variances are given by numbers at the top-left in PC plots. The correlation coefficients between the observed and simulated PCs are also presented at the topright 
both observation and simulations, the EOF1 mode displays a clear negative phase over southern China and positive phase over the YRB and northern China, representing the seasonal variation of precipitation associated with the broad-scale EASM. This mode accounts for 36.6, 34.9 and $35.9 \%$ to the total variances in the observation, DEF and OPT simulations, respectively. The correlation coefficients of the observed principal component (PC) with the two simulated PCs are close ( 0.96 vs. 0.95$)$ for the EOF1 mode. However, the spatial pattern in the OPT simulation exhibits better agreements with observation, while in the DEF simulation the positive anomaly center is too north compared with observation. The EOF2 mode represents a subseasonal oscillation with negative phase over most eastern China and positive phase over the southeast coastal region and center-north area. This mode accounts for 14.9, 14.3 and $14.8 \%$ to the total variances in the observation, DEF and OPT simulations, respectively. The correlation coefficient between the observed and simulated PC is slightly improved by applying the optimized parameters ( 0.79 vs. 0.7 in the default result).

\section{Conclusion and discussion}

Currently, the modeling of the East Asian summer monsoon (EASM) and its associated precipitation is still a challenging task in the climate community, which is highly related to the uncertainties within the precipitation parameterizations. In this study, several key parameters in the Kain-Fritsch scheme are calibrated over the EASM region in the WRF RCM. The importance-sampling algorithm MVFSA (i.e. Multiple Very Fast Simulated Annealing) is employed here during 3 years with weak, normal and strong EASM intensities, respectively. The impacts of the calibrated parameters on the simulated summer mean, south-north gradient and seasonal propagation of precipitation associated with the EASM are also investigated.

Our results show that the model sensitivity and optimized values of parameters are similar across years with different EASM intensities. By applying the optimized parameters, the precipitation magnitude and pattern as well as the surface energy features are better simulated by the WRF. The parameters related to downdraft, entrainment coefficients and CCT can most sensitively affect the precipitation and associated atmospheric features. It shows larger downdraft coefficient or CCT cause a wetter (dryer) condition at low (upper) layer and thus more low-level clouds, while the enhanced entrainment introduces more moisture to the mid-level atmosphere but prevents the updraft from penetrating further upward. The increase of downdraft or CCT can significantly decrease (increase) the frequency of heavy (light) precipitation, while the enhanced entrainment delays the development of convection but build up more atmospheric instability and water vapor, favoring the occurrence of heavy rainfall events and causing a possible northward shift of rainfall distribution. In general, the downdraft coefficient is more important for the total precipitation amount, while the entrainment coefficient and CCT play more important roles in the rainfall diurnal cycles. Prominent spatial variability of precipitation responses to the parameters varying across years is also found. The CCT is the most important for convection over wet regions with strong rainfall, while the downdraft parameter plays more important roles over northern regions where the dry condition induces more rainwater evaporation in the downdraft.

Long-term simulations (10-summer) confirm that by applying the identified optimized parameters the overestimated precipitation and heavy rain events are remarkably reduced. The precipitation patterns in both weak EASM and strong EASM years are better simulated with the optimized parameters. Due to more reasonable condensational heating of precipitation, the simulated monsoon circulations are also improved to some extent. In the standard WRF, the retreating (beginning) of Mei-yu (northern China rainfall) is much earlier than in observation, while with the optimized parameters the model produces better agreements with observation. Therefore, the simulated precipitation distributions at different rainy stages, as well as the simulated seasonal and sub-seasonal variations of the monsoon precipitation, are improved with the optimized parameters.

A number of limitations should be taken into account and deserve future research. First, the total precipitation (daily) is used for constraining the calibration process in this study, but compensating errors may exist among different rainfall types, e.g. convective versus stratiform precipitation, and daytime versus nighttime precipitation. The formation mechanisms and vertical heating profiles for convective and straiform precipitation are fundamentally different with each other (Hagos et al. 2010). Xu (2012) applied the TRMM observation and revealed that the EASM precipitation features could vary significantly with different convective and stratiform ratios during different rainy stages. Besides that, large biases of the rainfall diurnal cycle also exist over some specific regions, which may induce important effects on the simulated climate during both daytime and nighttime (Zhou et al. 2008). Therefore, calibration for different precipitation types is necessary in the future, but additional parameters from microphysical and macrophysical schemes need to be taken into account as the stratiform or nocturnal precipitation is mainly contributed by the microphysical process in the model (Dai 2006; Yang et al. 2013; Yuan et al. 2013; Zhao et al. 2013). The criteria for the onset of moist convection 
may also be important for the simulated diurnal features of precipitation (Dai et al. 1999).

Second, the precipitation is a product affected by many interacting processes. It is found that the simulated precipitation is very sensitive to the selections of radiative or PBL schemes (Cha et al. 2008; Yang et al. 2012). Even with the optimized parameters, there still exists a circulation bias resulting from the impropriate radiative or PBL process in the model (Cha et al. 2008). It is also possible that in this study, the misrepresenting of processes other than convection may cause the precipitation bias and the calibration of convection parameterization may just tune the parameters toward compensating such errors. However, the equilibrium EASM climate system is maintained mostly as a balance between atmospheric ascent cooling and precipitation condensational heating (Sampe and Xie 2010). As the prominent non-uniform features of rainfall distribution, the overestimated precipitation may further induce or exaggerate the circulation biases at various scales, indicating the important roles of precipitation feedback on the circulation and rainfall distribution (as our results have shown). Despite the possible compensating errors, the results from sensitivity analyses and optimal parameter values obtained in this study are still useful for the development of convective parameterization and better understanding the physical process in convective systems in climate models.

Third, the simulated precipitation and cloud features will certainly affect the land and ocean properties by influencing the energy and water flux exchange at surface. The impacts of the improved convection on the atmosphere-ocean and atmosphere-land interactions deserve further investigations with coupled climate models.

Fourth, the experiments in this study are designed to focus on the simulated precipitation over the EASM region, specifically over eastern China. However, the EASM precipitation is largely affected and interacting with the convective activities over the western tropical Pacific, Indian monsoon region, and so on (Kosaka and Nakamura 2006, 2010). A modeling study with GCM by Yang et al. (2013) showed that the EASM precipitation was related to the simulation of convection over the ITCZ (i.e. inter-tropical convergence zone) to some degree. How will the precipitation respond to the convective parameters over these regions in the WRF, and how will it influence the EASM precipitation are important questions for the simulation and prediction of the EASM precipitation (Hsu and Lin 2007). Furthermore, the relative importance of the local and remote impacts of parameter tuning also deserves further researches.

Fifth, the optimal convective parameters are identified based on simulations reinitialized every two days but validated in long-term simulations in this study. This approach is appropriate since this study focuses on the convection, which is a fast process and its life time is usually less than 2 days. However, the optimal values could be different if the model is freely run within 1 month. Future work is needed to further explore the transferability of optimized parameters across weather and climate scales featured with fundamentally different feedback mechanisms. In future studies, we intend to compare model response and performance based on optimization processes in free running mode versus constrained mode (i.e. reinitialization or nudging). Besides that, only the optimal parameters in 2007 are used in the 10-summer simulations here. It would be better if all the optimal parameter sets identified in years with respectively weak, normal and strong EASMs are applied in the long-term simulations to further confirm the conclusion in this study. Finally, large uncertainties are expected within the observational and reanalysis dataset used to constrain the optimization process or lateral boundary forcing (Gong and Wang 2000; Xu and Powell 2010), thus different sources for observation and reanalysis data should be applied to obtain more robust results in the future.

Acknowledgments The authors acknowledge two anonymous reviewers and the editor for their constructive comments and suggestions. This work is jointly supported by the National Natural Science Foundation of China (41305084 and 41175086), Special Program for China Meteorology Trade (GYHY201306020), the National Basic Research Program of China (973 Program, 2012CB955901) and the Jiangsu Collaborative Innovation Center for Climate Change. The contribution of Yun Qian in this study is supported by the U.S. Department of Energy's Office of Science as part of the Regional and Global Climate Modeling Program. The Pacific Northwest National Laboratory is operated for DOE by Battelle Memorial Institute under contract DE-AC05-76RL01830.

Open Access This article is distributed under the terms of the Creative Commons Attribution License which permits any use, distribution, and reproduction in any medium, provided the original author(s) and the source are credited.

\section{References}

Arai M, Kimoto M (2007) Simulated interannual variation in summertime atmospheric circulation associated with the East Asian monsoon. Clim Dyn 31(4):435-447. doi:10.1007/s00382007-0317-y

Arakawa A (2004) The cumulus parameterization problem: past, present, and future. J Clim 17(13):2493-2525

Arakawa A, Schubert WH (1974) Interaction of a cumulus cloud ensemble with large-scale environment, part I. J Atmos Sci 31(3):674-701

Bechtold P, Bazile E, Guichard F, Mascart P, Richard E (2001) A mass-flux convection scheme for regional and global models. Q J R Meteorol Soc 127(573):869-886

Bechtold P, Kohler M, Jung T, Doblas-Reyes F, Leutbecher M, Rodwell MJ, Vitart F, Balsamo G (2008) Advances in simulating atmospheric variability with the ECMWF model: from synoptic to decadal time-scales. Q J R Meteorol Soc 134(634):1337-1351. doi:10.1002/Qj.289 
Berner J, Jung T, Palmer TN (2012) Systematic model error: the impact of increased horizontal resolution versus improved stochastic and deterministic parameterizations. J Clim 25(14):4946-4962. doi:10.1175/Jcli-D-11-00297.1

Cha DH, Lee DK, Hong SY (2008) Impact of boundary layer processes on seasonal simulation of the East Asian summer monsoon using a Regional Climate Model. Meteorol Atmos Phys 100(1-4):53-72. doi:10.1007/s00703-008-0295-6

Chang E-C, Yeh S-W, Hong S-Y, Wu R (2013) Sensitivity of summer precipitation to tropical sea surface temperatures over East Asia in the GRIMs GMP. Geophys Res Letts 40(9):1824-1831. doi:10.1002/grl.50389

Chen F, Dudhia J (2001) Coupling an advanced land surfacehydrology model with the Penn State-NCAR MM5 modeling system. Part I: model implementation and sensitivity. Mon Weather Rev 129(4):569-585

Chen H, Zhou T, Neale RB, Wu X, Zhang GJ (2010) Performance of the new NCAR CAM3.5 in East Asian summer monsoon simulations: sensitivity to modifications of the convection scheme. J Clim 23(13):3657-3675. doi:10.1175/2010jcli3022.1

Cheng HQ, Wu TW, Dong WJ (2008) Thermal contrast between the middle-latitude Asian continent and adjacent ocean and its connection to the East Asian summer precipitation. J Clim 21(19):4992-5007. doi:10.1175/2008jcli2047.1

Dai A (2006) Precipitation characteristics in eighteen coupled climate models. J Clim 19(18):4605-4630

Dai A, Giorgi F, Trenberth KE (1999) Observed and model-simulated diurnal cycles of precipitation over the contiguous United States. J Geophys Res 104(D6):6377. doi:10.1029/98jd02720

Ding YH (1992) Summer monsoon rainfalls in China. J Meteorol Soc Jpn 70(1B):373-396

Ding YH (1994) Monsoons over China. Kluwer Academic Publisher, Dordrecht, p 419

Ding YH, Chan JCL (2005) The East Asian summer monsoon: an overview. Meteorol Atmos Phys 89(1-4):117-142. doi:10.1007/ s00703-005-0125-Z

Ding YH, Shi XL, Liu YM, Liu Y, Li QQ, Qian FF, Miao QQ, Zhai QQ, Gao K (2006) Multi-year simulations and experimental seasonal predictions for rainy seasons in China by using a nested regional climate model (RegCM_NCC). Part I: sensitivity study. Adv Atmos Sci 23(3):323-341. doi:10.1007/s00376-006-0323-8

Done JM, Craig GC, Gray SL, Clark PA, Gray MEB (2006) Mesoscale simulations of organized convection: importance of convective equilibrium. Q J R Meteorol Soc 132(616):737-756. doi:10.1256/Qj.04.84

Emanuel KA, Zivkovic-Rothman M (1999) Development and evaluation of a convection scheme for use in climate models. J Atmos Sci 56(11):1766-1782

Emanuel KA, Neelin JD, Bretherton CS (1994) On large-scale circulations in convecting atmospheres. Q J R Meteorol Soc 120(519):1111-1143

Enomoto T, Hoskins BJ, Matsuda Y (2003) The formation mechanism of the Bonin high in August. Q J R Meteorol Soc 129(587):157-178. doi:10.1256/Gj.01.211

Fang YJ, Zhang YC, Huang AN, Li B (2013) Seasonal and intraseasonal variations of East Asian summer monsoon precipitation simulated by a regional air-sea coupled model. Adv Atmos Sci 30(2):315-329. doi:10.1007/s00376-012-1241-6

Fu CB, Wang SY, Xiong Z, Gutowski WJ, Lee DK, McGregor JL, Sato Y, Kato H, Kim JW, Suh MS (2005) Regional climate model intercomparison project for Asia. Bull Am Meteorol Soc 86(2):257-266. doi:10.1175/Bams-86-2-257

Gong W, Wang WC (2000) A regional model simulation of the 1991 severe precipitation event over the Yangtze-Huai River valley, Part II: model bias. J Clim 13(1):93-108. doi:10.1175/15200442(2000)013<0093:Armsot>2.0.Co;2
Gregory D, Morcrette JJ, Jakob C, Beljaars ACM, Stockdale T (2000) Revision of convection, radiation and cloud schemes in the ECMWF Integrated Forecasting System. Q J R Meteorol Soc 126(566): 1685-1710

Grell GA, Devenyi D (2002) A generalized approach to parameterizing convection combining ensemble and data assimilation techniques. Geophys Res Letts 29(14). doi:10.1029/ 2002GL015311

Hagos S, Zhang CD, Tao WK, Lang S, Takayabu YN, Shige S, Katsumata M, Olson B, L'Ecuyer T (2010) Estimates of tropical diabatic heating profiles: commonalities and uncertainties. J Clim 23(3):542-558. doi:10.1175/2009jcli3025.1

Harrison DE, Romea RD, Hankin SH (2001) Central equatorial Pacific zonal currents. I: The Sverdrup balance, nonlinearity and tropical instability waves. Annu Mean Dyn J Mar Res 59(6):895-919. doi:10.1357/00222400160497706

Hsu H-H, Lin S-M (2007) Asymmetry of the tripole rainfall pattern during the East Asian summer. J Clim 20(17):4443-4458. doi:10.1175/jcli4246.1

Ingber L (1989) Very fast simulated re-annealing. Math Comput Model 12(8):967-973

Jackson C, Sen MK, Stoffa PL (2004) An efficient stochastic Bayesian approach to optimal parameter and uncertainty estimation for climate model predictions. J Clim 17(14):2828-2841

Jackson CS, Sen MK, Huerta G, Deng Y, Bowman KP (2008) Error reduction and convergence in climate prediction. J Clim 21(24):6698-6709. doi:10.1175/2008jcli2112.1

Janjić ZI (1994) The step-mountain eta coordinate model-further developments of the convection, viscous sublayer, and turbulence closure schemes. Mon Weather Rev 122(5):927-945

Janjić ZI (2002) Nonsingular implementation of the Mellor-Yamada level 2.5 scheme in the NCEP Meso model. NCEP office note 437:61

Kain JS (2004) The Kain-Fritsch convective parameterization: an update. J Appl Meteorol 43(1):170-181

Kain JS, Fritsch JM (1990) A one-dimensional entraining detraining plume model and its application in convective parameterization. J Atmos Sci 47(23):2784-2802

Kang IS, Ho CH, Lim YK, Lau KM (1999) Principal modes of climatological seasonal and intraseasonal variations of the Asian summer monsoon. Mon Weather Rev 127(3): 322-340. doi:10.1175/1520-0493(1999)127<0322:Pmocsa $>2$. $0 . \mathrm{Co} ; 2$

Kosaka Y, Nakamura H (2006) Structure and dynamics of the summertime Pacific-Japan teleconnection pattern. Q J R Meteorol Soc 132(619):2009-2030. doi:10.1256/qj.05.204

Kosaka Y, Nakamura H (2010) Mechanisms of meridional teleconnection observed between a summer monsoon system and a subtropical anticyclone. Part I: the Pacific-Japan pattern. J Clim 23(19):5085-5108. doi:10.1175/2010jcli3413.1

Kosaka Y, Xie S-P, Nakamura H (2011) Dynamics of interannual variability in summer precipitation over East Asia. J Clim 24(20):5435-5453. doi:10.1175/2011jcli4099.1

Kreitzberg CW, Perkey DJ (1976) Release of potential instability. 1. Sequential plume model within a hydrostatic primitive equation model. J Atmos Sci 33(3):456-475

Krishnamurti TN (1985) Summer monsoon experiment-a review. Mon Weather Rev 113(9):1590-1626. doi:10.1175/15200493(1985)113<1590:Smer>2.0.Co;2

Lau KM, Kim KM, Yang S (2000) Dynamical and boundary forcing characteristics of regional components of the Asian summer monsoon. J Clim 13(14):2461-2482. doi:10.1175/1520-0442 (2000)013<2461:Dabfco $>2.0 . C o ; 2$

Lee D-K, Suh M-S (2000) Ten-year east Asian summer monsoon simulation using a regional climate model (RegCM2). J Geophys Res 105(D24):29565. doi:10.1029/2000jd900438 
Leung LR, Ghan SJ, Zhao ZC, Luo Y, Wang WC, Wei HL (1999) Intercomparison of regional climate simulations of the 1991 summer monsoon in eastern Asia. J Geophys Res 104(D6):6425. doi:10.1029/1998jd200016

Leung LR, Mearns LO, Giorgi F, Wilby RL (2003) Regional climate research. Bull Am Meteorol Soc 84(1):89-95. doi:10.1175/ bams-84-1-89

Leung LR, Zhong SY, Qian Y, Liu YM (2004) Evaluation of regional climate simulations of the 1998 and 1999 East Asian summer monsoon using the GAME/HUBEX observational data. J Meteorol Soc Jpn 82(6):1695-1713. doi:10.2151/Jmsj.82.1695

Lin ZD, Lu RY (2008) Abrupt northward jump of the East Asian upper-tropospheric jet stream in mid-summer. J Meteorol Soc Jpn 86(6):857-866

Liu YQ, Avissar R, Giorgi F (1996) Simulation with the regional climate model RegCM2 of extremely anomalous precipitation during the 1991 East Asian flood: an evaluation study. J Geophys Res 101(D21):26199-26215. doi:10.1029/96jd01612

Liu YM, Chan JCL, Mao JY, Wu GX (2002) The role of Bay of Bengal convection in the onset of the 1998 South China Sea summer monsoon. Mon Weather Rev 130(11):2731-2744. doi:10.1175/1520-0493(2002)130<2731:Trobob $>2.0$. Co; 2

Lu R, Lin Z (2009) Role of subtropical precipitation anomalies in maintaining the summertime meridional teleconnection over the Western North Pacific and East Asia. J Clim 22(8):2058-2072. doi:10.1175/2008jcli2444.1

Mao JY, Sun Z, Wu GX (2010) 20-50-day oscillation of summer Yangtze rainfall in response to intraseasonal variations in the subtropical high over the western North Pacific and South China Sea. Clim Dyn 34(5):747-761. doi:10.1007/s00382-009-0628-2

Mlawer EJ, Taubman SJ, Brown PD, Iacono MJ, Clough SA (1997) Radiative transfer for inhomogeneous atmospheres: RRTM, a validated correlated-k model for the longwave. J Geophys Res 102(D14):16663-16682. doi:10.1029/97jd00237

Morrison H, Curry JA, Khvorostyanov VI (2005) A new doublemoment microphysics parameterization for application in cloud and climate models. Part I: description. J Atmos Sci 62(6): $1665-1677$

Müller MD, Scherer D (2005) A grid- and subgrid-scale radiation parameterization of topographic effects for mesoscale weather forecast models. Mon Weather Rev 133(6):1431-1442. doi:10. 1175/Mwr2927.1

Park EH, Hong SY, Kang HS (2008) Characteristics of an East-Asian summer monsoon climatology simulated by the RegCM3. Meteorol Atmos Phys 100(1-4):139-158. doi:10.1007/s00703008-0300-0

Pincus R, Barker HW, Morcrette JJ (2003) A fast, flexible, approximate technique for computing radiative transfer in inhomogeneous cloud fields. J Geophys Res 108(D13):4376. doi:10.1029/2002JD003322

Qian Y, Leung LR (2007) A long-term regional simulation and observations of the hydroclimate in China. J Geophys Res 112(D14):D14104. doi:10.1029/2006jd008134

Qian Y, Flanner MG, Leung LR, Wang W (2011) Sensitivity studies on the impacts of Tibetan Plateau snowpack pollution on the Asian hydrological cycle and monsoon climate. Atmos Chem Phys 11(5):1929-1948. doi:10.5194/acp-11-1929-2011

Rodell M, Houser PR, Jambor U, Gottschalck J, Mitchell K, Meng CJ, Arsenault K, Cosgrove B, Radakovich J, Bosilovich M, Entin JK, Walker JP, Lohmann D, Toll D (2004) The global land data assimilation system. Bull Am Meteorol Soc 85(3):381-394. doi:10.1175/Bams-85-3-381

Sampe T, Xie S-P (2010) Large-scale dynamics of the Meiyu-Baiu Rainband: environmental forcing by the westerly jet*. J Clim 23(1):113-134. doi:10.1175/2009jcli3128.1
Simpson J, Wiggert V (1969) Models of precipitating cumulus towers. Mon Weather Rev 97(7):471-489

Skamarock WC, Klemp JB, Dudhia J, Gill DO, Barker DM, Duda MG, Huang X-Y, Wang W, Powers JG (2008) A description of the advanced research WRF version 3. NCAR technical note NCAR/TN-475 + STR, p 123

Song X, Zhang GJ (2011) Microphysics parameterization for convective clouds in a global climate model: description and single-column model tests. J Geophys Res 116(D2):D02201. doi:10.1029/2010jd014833

Tao S, Chen L (1987) A review of recent research on the East Asian summer monsoon. In: Chang C-P, Krishnamurti TN (eds) China, monsoon meteorology. Oxford University Press, Oxford, pp 60-92

Trier SB, Chen F, Manning KW, LeMone MA, Davis CA (2008) Sensitivity of the PBL and precipitation in 12-Day simulations of warm-season convection Using different land surface models and soil wetness conditions. Mon Weather Rev 136(7): 2321-2343. doi:10.1175/2007mwr2289.1

Villagran A, Huerta G, Jackson CS, Sen MK (2008) Computational methods for parameter estimation in climate models. Bayesian Anal 3(4):823-850. doi:10.1214/08-BA331

Wang B, Fan Z (1999) Choice of south Asian summer monsoon indices. Bull Am Meteorol Soc 80(4):629-638. doi:10.1175/ 1520-0477(1999)080<0629:Cosasm>2.0.Co;2

Wang B, Xu XH (1997) Northern hemisphere summer monsoon singularities and climatological intraseasonal oscillation. J Clim 10(5):1071-1085. doi:10.1175/1520-0442(1997)010<1071: Nhsmsa $>2.0 . \mathrm{Co} ; 2$

Wang B, Wu RG, Fu XH (2000a) Pacific-East Asian teleconnection: how does ENSO affect East Asian climate? J Clim 13(9): 1517-1536. doi:10.1175/1520-0442(2000)013<1517:Peathd $>2$. $0 . \mathrm{Co} ; 2$

Wang WC, Gong W, Wei HL (2000b) A regional model simulation of the 1991 severe precipitation event over the Yangtze-Huai River valley. Part I: precipitation and circulation statistics. J Clim 13(1):74-92. doi:10.1175/1520-0442(2000)013<0074:Armsot>2.0.Co;2

Wang YQ, Sen OL, Wang B (2003) A highly resolved regional climate model (IPRC-RegCM) and its simulation of the 1998 severe precipitation event over China. Part I: model description and verification of simulation. J Climate 16(11):1721-1738. doi:10.1175/1520-0442(2003)016<1721:Ahrrcm > 2.0.Co;2

Wang B, Bao Q, Hoskins B, Wu G, Liu Y (2008a) Tibetan Plateau warming and precipitation changes in East Asia. Geophys Res Letts 35(14):L14702. doi:10.1029/2008g1034330

Wang B, Wu Z, Li J, Liu J, Chang C-P, Ding Y, Wu G (2008b) How to measure the strength of the East Asian summer monsoon. J Clim 21(17):4449-4463. doi:10.1175/2008jcli2183.1

Wu TW (2012) A mass-flux cumulus parameterization scheme for large-scale models: description and test with observations. Clim Dyn 38(3-4):725-744. doi:10.1007/s00382-011-0995-3

Xiao CL, Zhang YC (2012) The East Asian upper-tropospheric jet streams and associated transient eddy activities simulated by a climate system model BCC_CSM1.1. Acta Meteorol Sin 26 (6):700-716. doi:10.1007/s13351-012-0603-4

$\mathrm{Xu} \mathrm{W} \mathrm{(2012)} \mathrm{Precipitation} \mathrm{and} \mathrm{convective} \mathrm{characteristics} \mathrm{of} \mathrm{summer}$ deep convection over East Asia observed by TRMM. Mon Weather Rev 1577-1592. doi:10.1175/mwr-d-12-00177.1

Xu JJ, Powell AM (2010) Ensemble spread and its implication for the evaluation of temperature trends from multiple radiosondes and reanalyses products. Geophys Res Letts 37:L17704. doi:10.1029/ $2010 \mathrm{~g} 1044300$

Yan H, Qian Y, Lin G, Leung LR, Yang B, Fu Q (2014) Parametric sensitivity and calibration for Kain-Fritsch convective parameterization scheme in the WRF model. Clim Res (in press) 
Yang B, Qian Y, Lin G, Leung LR, Zhang YC (2012) Some issues in uncertainty quantification and parameter tuning: a case study of convective parameterization scheme in the WRF regional climate model. Atmos Chem Phys 12:2409-2427. doi:10.5194/ acp-12-2409-2012

Yang B, Qian Y, Lin G, Leung LR, Rasch PJ, Zhang GJ, McFarlane SA, Zhao C, Zhang YC, Wang HL, Wang MH, Liu XH (2013) Uncertainty quantification and parameter tuning in the CAM5 Zhang-McFarlane convection scheme and impact of improved convection on the global circulation and climate. J Geophys Res 118(2):395-415. doi:10.1029/2012jd018213

Ye D-Z, Huang R-H (1996) Study on the regularity and formation reason of drought and flood in the Yangtze and Huaihe River Regions (in Chinese). Shandong Science and Technology Press, Jinan, Shandong province, China, p 387

Yhang Y-B, Hong S-Y (2008) Improved physical processes in a regional climate model and their impact on the simulated summer monsoon circulations over East Asia. J Clim 21(5):963-979. doi:10.1175/ 2007jcli1694.1

Yu ET, Wang HJ, Gao YQ, Sun JQ (2011) Impacts of cumulus convective parameterization schemes on summer monsoon precipitation simulation over China. Acta Meteorol Sin 25(5):581-592. doi:10.1007/s13351-011-0504-y

Yuan W, Yu R, Zhang M, Lin W, Li J, Fu Y (2013) Diurnal cycle of summer precipitation over subtropical East Asia in CAM5. J Clim 26(10):3159-3172. doi:10.1175/jcli-d-12-00119.1

Zhang YC, Huang DQ (2011) Has the East Asian westerly jet experienced a poleward displacement in recent decades? Adv Atmos Sci 28(6):1259-1265. doi:10.1007/s00376-011-9185-9
Zhang GJ, McFarlane NA (1995) Sensitivity of climate simulations to the parameterization of cumulus convection in the Canadian climate center general-circulation model. Atmos Ocean 33(3):407-446

Zhang L, Ding Y, Sun Y (2008) Evaluation of precipitation simulation in East Asian monsoon areas by coupled ocean atmosphere general circulation models. Chinese J Atmos Sci (in Chinese) 32(2):261-276

Zhao C, Liu X, Qian Y, Yoon J, Hou Z, Lin G, McFarlane S, Wang H, Yang B, Ma P-L, Yan H, Bao J (2013) A sensitivity study of radiative fluxes at the top of atmosphere to cloud-microphysics and aerosol parameters in the community atmosphere model CAM5. Atmos Chem Phys Discuss 13:12135-12176. doi:10. 5194/acpd-13-12135-2013

Zhou TJ, Li Z (2002) Simulation of the East Asian summer monsoon using a variable resolution atmospheric GCM. Clim Dyn 19(2):167-180. doi:10.1007/s00382-001-0214-8

Zhou TJ, Yu RC (2005) Atmospheric water vapor transport associated with typical anomalous summer rainfall patterns in China. J Geophys Res 110(D8):D08104. doi:10.1029/2004jd005413

Zhou TJ, Yu RC, Chen HM, Dai A, Pan Y (2008) Summer precipitation frequency, intensity, and diurnal cycle over China: a comparison of satellite data with rain gauge observations. J Clim 21(16):3997-4010. doi:10.1175/2008jcli2028.1

Zou L, Zhou T (2011) Sensitivity of a regional ocean-atmosphere coupled model to convection parameterization over western North Pacific. J Geophys Res 116(D18):D18106. doi:10.1029/ $2011 \mathrm{jd} 015844$ 